\title{
IDŐJÁRÁS
}

Quarterly Journal of the Hungarian Meteorological Service

Vol. 123, No. 4, October-December, 2019, pp. 551-576

\section{A new index for climate change evaluation - An example with the ALADIN and RegCM regional models for the Balkans and the Apennines}

\author{
Valery Spiridonov and Rilka Valcheva* \\ National Institute of Meteorology and Hydrology (NIMH) \\ 66, Tsarigradsko Shose blvd Sofia 1784, Bulgaria \\ *Corresponding Author e-mail: Rilka.Valcheva@gmail.com \\ (Manuscript received in final form October 31, 2018)
}

\begin{abstract}
A new index for climate change assessment has been introduced. It is a ratio between the number of cases from a future period and the cases of a control experiment (reference period) falling within a predefined interval of the reference period. By "case" we mean the value of a meteorological element that meets certain conditions. Additionally, its conservation is a necessary condition for reducing the risk of losing a reliable signal of the modeled variability of future climate when applying bias correction methods (BCM's). The spatial distribution of this index is presented by using two regional climate models, ALADIN and RegCM4, over an area including the Balkan and Apennine Peninsulas. The assessment is performed for the average monthly temperature and precipitation. Both models have similar indices in broad areas. In winter, spring, and summer this refers to temperature and in spring and summer to rainfall.
\end{abstract}

Key-words: climate change, new index, ALADIN, RegCM4, bias correction

\section{Introduction}

For assessment of climate change by numerical model experiments, we usually consider differences (tendencies) between the future and a reference (control) period. Thus, to a certain extent, the systematic error of the simulations is 
compensated. This difference can be added to actual observations to obtain future values. In some papers this method is mentioned as "delta change" approach (Teutschbein et al., 2011). Later, this method will be described. Although, the models are deterministic, their results are often postprocessed by statistical methods as random processes. There are two main reasons for applying the statistical approaches. The first one is statistical downscaling when the climate model grid resolution is quite coarse. This is usually the case with global climate models. "Downscaling" is a method of obtaining high-resolution climate or climate change information from relatively coarse-resolution global climate models (GCMs). The dynamical downscaling is achieved through regional climate models (RCM), such as RegCM and ALADIN. Statistical downscaling methods cover regression-type models including both linear and non-linear relationships established between the output of the model and a more dense set of local observations (Mearns et al., 1999; Huth, 1999). In addition to achieving a finer resolution, some of these methods also eliminate systematic errors (biases). This gives the idea to change the results of dynamical downscaling to match observations. Numerous methods for such modification are known as "bias correction methods" (BCMs). This procedure is necessary in many cases, when we use climate model results as input data for other impact models such as hydrological, agricultural (Navarro-Racines et al., 2015; Haerter et al., 2015), and air quality models. In this case, it is necessary to use the daily values from the output of dynamic models. Consequently, the output of dynamic models must be adjusted to match the statistical structure of daily observations. An example of this is the so-called "drizzle" problem (Dai, 2006). By this terminology the trend of the climate models to precipitate too frequently at reduced intensity is denoted. Such an input for hydrological models makes them unusable. The term "bias correction" includes much more transformation than the simple removing of bias between model results and observations. The transformation of the model results from the so-called control or reference experiment (run) is used to match them to the observing data or other data considered as reference, for example to re-analyses. It is assumed that if the output of the model differs from observations in the same reference period, there will be a false signal in the future simulations. The applied techniques can be summarized by defining a "transfer function" between observed and reference (control) values, so that the obtained probability density function (pdf) (or cumulative density function cdf) corresponds to the measured data for the reference period or to the data considered as reference. Then, this "transfer function" is applied to the results obtained for the future period. Gaussian kernel (Sippel et al., 2016) and gamma distribution (Piani et al., 2010) as cumulative density function can be used. The distribution of Weibull is often applied to the wind. Various methods are used, such as "multiple linear regression", "analogue methods", "local intensity scaling", and "quantile mapping". After all, the result could be described as transformation of the probability density function or 
cumulative distribution function. The multiple linear regression method has a linear transfer function, but others may or may not have that property. If we denote pdf as $S$, the linearity means that after applying the linear transfer function $F(a, b)$, the new pdf (or $S^{\prime}$ ) should obey on the relation $S^{\prime}=a^{*} S+b$, where $a$ and $b$ are constants. The simplest case is when $a=0$. In this case $S$ moves at distance $b$ from its original position. Most of these methods are included in the software developed in Cattaneo et al. (2015). In Deque (2007) another method is described which is similar to quantile mapping.

There are no observations in the future, so we have to rely on the assumption of correct extrapolation of these methods in the changing climate. As noted in Ehret et al. (2012): "however, in the context of CCIS (Climate Change Impact Studies), the definition of bias is not as strict: it varies with the scope of the studies and is often used in a general sense for addressing any deviation of interest (e.g., with respect to mean, variance, covariance, length of dry spells, etc.) of the model from the corresponding "true" value ". A critical analysis and review of the most commonly used methods can be found in Maraun (2016).

Here, we propose a way to avoid the risk of losing a reliable climate change signal when using some BCM's. Some may lead to the loss of an otherwise properly predicted change. As it is mentioned in Grillakis et al. (2017): "However, it is well known that quantile mapping may significantly modify the long-term statistics due to the time dependency of the temperature bias". In many BCM's, the different meteorological fields are treated independently. That may lead to some discrepancies. For example, hydrological impact models require assessment of evaporation and evapotranspiration. This means consistency between changes in temperature, wind, and solar radiation. The separate correction loses the relationships between them. As noted in Hagemann et al. (2011): "Some more uncertainties have occurred over several dry regions and seasons, especially for precipitation. Here, any projected changes in discharge and their subsequent impact on water resources have to be carefully considered, with and without using bias corrected GCM data" In Dosio (2016) a possible distortion of the climate change signal is noted: "The mean climate change is conserved by bias adjustment only if the bias is constant, which is not the case for the RCMs' results over large part of Europe". Here the effect of bias correction on a number of climate indices from the Expert Team on Climate Change Detection and Indices (ETCCDI) have been investigated. In Pierce et al., (2015) it is mentioned: "The quantile mapping and cumulative distribution function transform can significantly alter the global climate model's mean climate change signal, with differences of up to $2{ }^{\circ} \mathrm{C}$ and $30 \%$ points for monthly mean temperature and precipitation, respectively". Different approaches to BCM's attempt to avoid potential drawbacks. Preservation of the originally modeled long-term signal in the mean, the standard deviation and higher and lower percentiles of temperature is investigated in Grillakis et al. 
(2017). A method for reducing errors in the models' simulation of variance as a function of frequency is proposed in Pierce et al. (2015). In Switanek et al. (2017), instead of quantile mapping, a scaled distribution mapping technique is developed. The question to be answered is "to what extent a certain bias correction method can be applied, and in which area it can be applied".

\section{Definition and properties of the proposed $C$-index for climate change evaluation}

The values of any meteorological element obtained through a reference (30year-long) period simulation, have various statistical distributions for each grid point of the model. The future period simulation (again 30 years) leads to a new distribution for each grid points. Let $X_{R}$ be the number of cases from the reference period that belong to an interval of a set of values $(\delta 1, \delta 2)$. Let $X_{F}$ be the number of cases from the future period that fall within the same interval from the reference period. The ratio

$$
C=X_{F} / X_{R}
$$

is another possible measure of climate change at each grid point. This ratio will be called "C-index". When $C<1$, the number of cases from the future period are less than those from the reference period for the defined interval, and when $\mathrm{C} \geq 1$ the number of cases from the future period are maintained or increased with regard to the reference period cases for the same interval. For example, the number of cases above a certain value during the reference period are compared to the cases of the future period. This measure has a "relativistic" meaning, i.e., how the future weather would look like for the observer from the reference (control) simulation period.

According to this definition, the necessary condition for any bias correction method, which should not cause distortion of pdf or cdf is that the value of $C$ (whatever it is) should not change. In other words, if $B$ is the "transfer function" mentioned above, then

$$
B\left(X_{F}\right) / B\left(X_{R}\right)=X_{F} / X_{R}=\mathrm{C}
$$

is the necessary condition that is valid only for the defined interval of C-index. This is a partial answer to the question raised above.

The conservation of $C$ depends on the bias correction method (BCM). We will show that the linear transformation ("linear transfer function") does not change this ratio. If the transfer function is non-linear, this feature is not guaranteed, but there may be an interval in which the $\mathrm{C}$-index remains unchanged. Another possibility is to approximate the non-linear function by a piecewise linear function. 
Let the values of an element (temperature, precipitation, etc.) from the future period fall within a certain interval before the transformation:

$$
X 1_{R}<X_{F}<X 2_{R},
$$

where $X 1_{R}$ and $X 2_{R}$ determine the interval of interest from the reference period in which the cases $X_{F}$ from the future period fall. We will prove that for any linear transformation:

$$
Y=A X+B
$$

for which, when $A \geq 0$ the future cases falling within this range are preserved, i.e.:

$$
A X 1_{R}+B<A X_{F}+B<A X 2_{R}+B .
$$

Let us consider the left inequality and assume the opposite,

$$
A X 1_{R}+B \geq A X_{F}+B
$$

or

$$
A\left(X 1_{R}-X_{F}\right) \geq 0 .
$$

When $A>0$, we get $X 1_{R} \geq X_{F}$, which contradict to Eq. (3). In the same way, the correctness of the right part of Eq. (5) is proved. Once this is true for all of the cases, it is also true for the ratio of their sum $C$. The particular case, $A=0$, is when probability density function (pdf) is only "moved" on the $X$-axis.

The proposed index is an indicator, which signs if the signal from the control run to the future one is changed by the applied "bias correction" method.

One important question is how stable the value of $C$ i.e., the ratio $X_{F} / X_{R}$ is. This depends on the inherent errors of the model (for example, as a result of accepted parameterizations, approximation of equations, etc.). The following equation Eq. (8) shows that if the error is proportional to the value of $X$, the ratio between the reference and the future simulation does not change. The "drizzle" effect mentioned above actually is an error of the magnitude of rainfall rates simulated by the model Dai (2006) and Sun et al. (2006). The error component proportional to the magnitude does not affect the C-index.

Let $k$ be the error coefficient, then:

$$
\left(X_{F}+k X_{F}\right) /\left(X_{R}+k X_{R}\right)=X_{F}(1+k) / X_{R}(1+k)=X_{F} / X_{R} .
$$


Note, that this index is determined separately for each point of the model's grid. So, instead of fixed thresholds, it is possible to have different intervals at each grid point. This will be illustrated in the next example.

\section{Example with an interval defined by standard deviation $\sigma$ and mean $\mu$}

We will illustrate the $\mathrm{C}$-index by looking at the change of the number of cases falling within a certain interval $(\delta 1=\mu-\sigma ; \delta 2=\mu+\sigma)$. The C-index is determined by the ratio of the number of cases of the future period and the reference period falling within this range defined by the mean $\mu$ and the standard deviation $\sigma$ of the reference period.

About $68 \%$ of values drawn from the Gaussian distribution are within one standard deviation $\sigma$ away from the mean $\mu$. Let the cases falling within this interval be considered as "normal", and the cases outside it as "extreme". When $C \geq 1$, more cases of the future period fall within this interval, i.e., in this definition the future period becomes "more normal" from the point of view of the "referent period simulation observer", and this change will not seriously affect the environment, but it is possible to have more cases of "extreme" weather outside this interval. When $C<1$, it means that less cases from the future period fall in the interval defined by the reference period, i.e., this can be considered as a sensitive climate change. The smaller the $C$, the greater the change.

Simulation results with the regional model ALADIN forced with boundary conditions from the ARPEGE global (A1B scenario) and RegCM4.4.5 regional climate models (Giorgi et al., 2012) forced with boundary conditions from the HadGEM2-ES global climate model (Hadley Centre Global Environment Model - Earth-System version 2, Collins et al., 2011) according to the RCP45 scenario (Thomson et al., 2011) were used. Both models have a resolution of $20 \mathrm{~km}$. In Figs. 1 and 2, the C-index distribution of the temperature value from ALADIN and RegCM4 models by seasons (winter - DJF; spring - MAM; summer - JJA; and autumn $-\mathrm{SON})$ is shown. Areas with $C \geq 1$ are marked in red $(C>1)$ and orange $(C=1)$ (actually, where the weather is "usual"). For $C<1$, the color gradation is by intervals of 0.2. In Figs. $1 a$ and $2 a$, temperature tendencies with ALADIN and RegCM4 models are shown, i.e., the difference between the future and reference periods by seasons in degrees Celsius $\left({ }^{\circ} \mathrm{C}\right)$. For the 2021-2050 period the warming trend is notable throughout the whole year for both models, especially during the JJA season. Similarly, in Figs. 3 and 4, the C-index distribution of precipitation values for both models is presented, while in Figs. $3 a$ and $4 a$, the tendencies for precipitation calculated by the two models are shown (in \%). Both models show less precipitation in summer (JJA) and more precipitation in spring (MAM). 

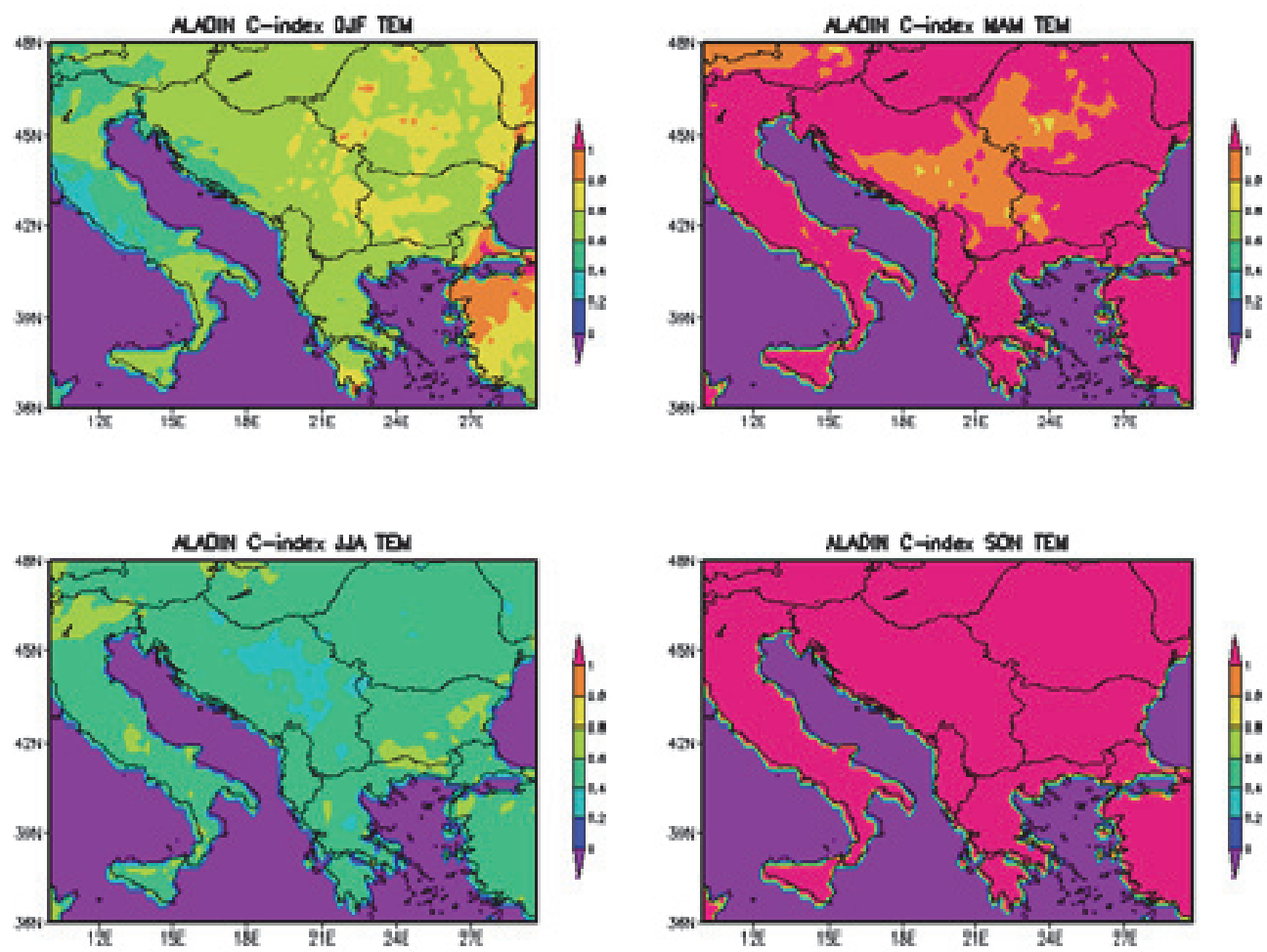

Fig. 1. Temperature C-index distribution from ALADIN model simulation for reference (1975-2004) and future (2021-2050) periods by seasons (winter - DJF; spring - MAM; summer - JJA; autumn - SON).
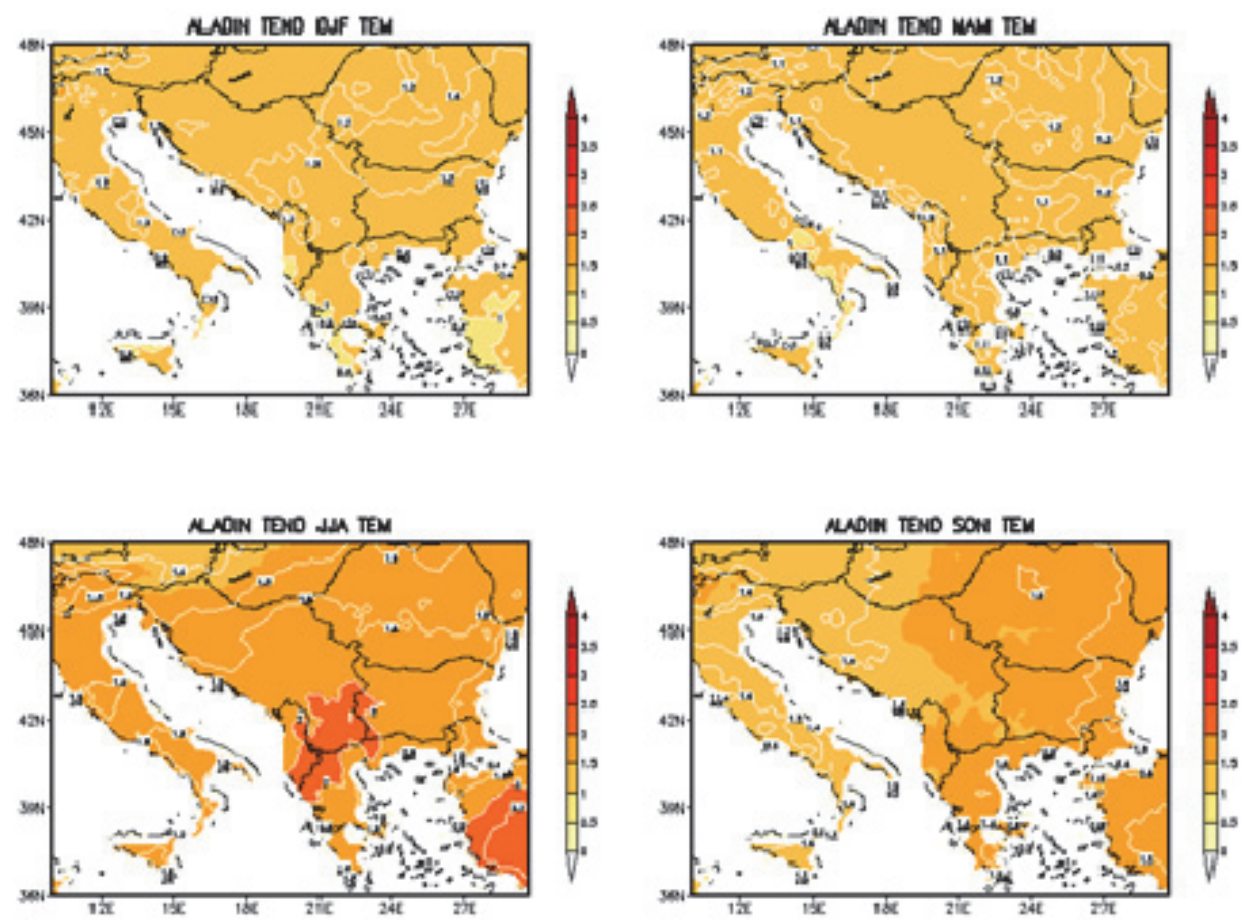

Fig. 1 a. Temperature tendencies with ALADIN model - difference between future (20212050) and reference (1975-2004) periods by seasons (winter - DJF; spring - MAM; summer - JJA; autumn - SON) in ${ }^{\circ} \mathrm{C}$. 

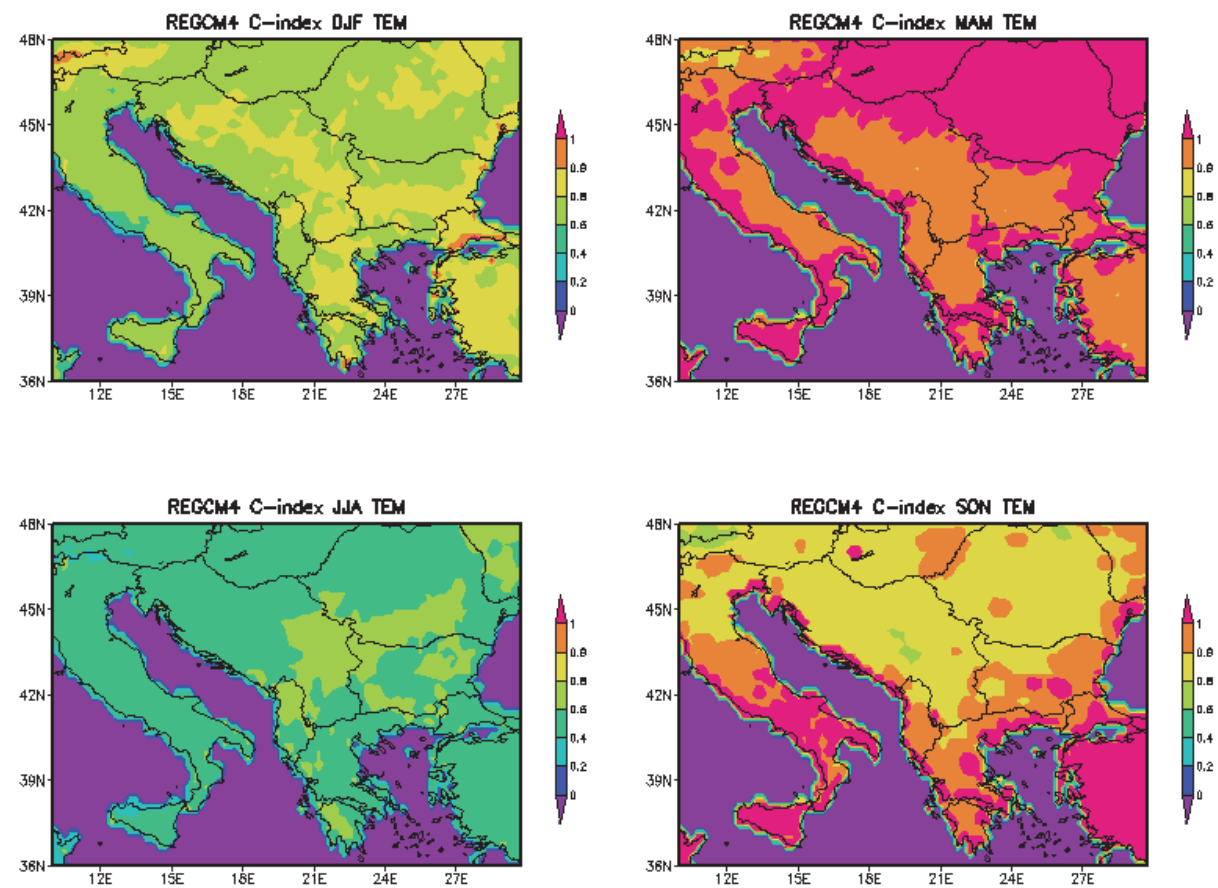

Fig. 2. Temperature C-index distribution from RegCM4 model simulation for the reference (1975-2004) and future (2021-2050) periods by seasons (winter - DJF; spring MAM; summer - JJA; autumn - SON).
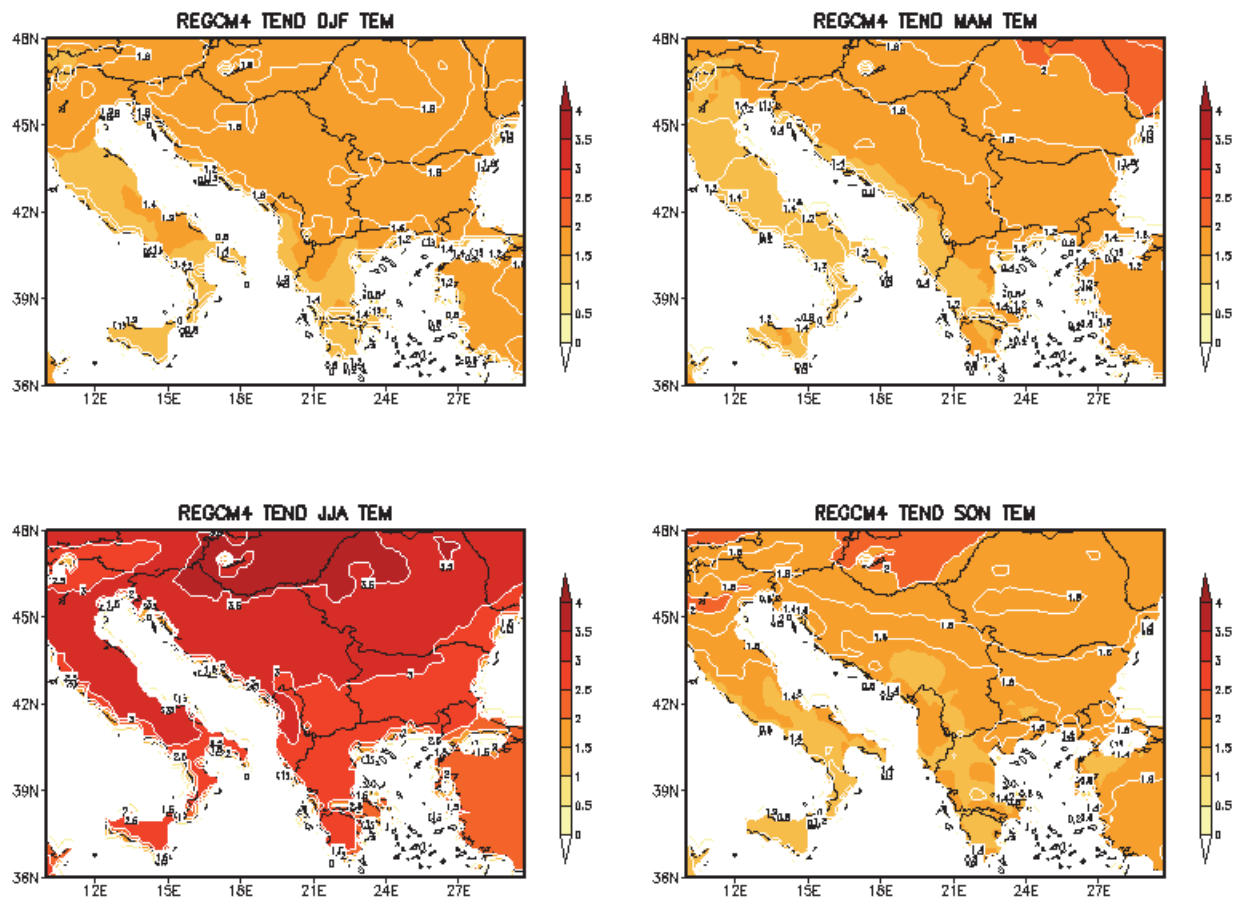

Fig. 2a. Temperature tendencies with RegCM4 model - difference between future (20212050) and reference (1975-2004) periods by seasons (winter - DJF; spring - MAM; summer - JJA; autumn - SON) in ${ }^{\circ} \mathrm{C}$. 

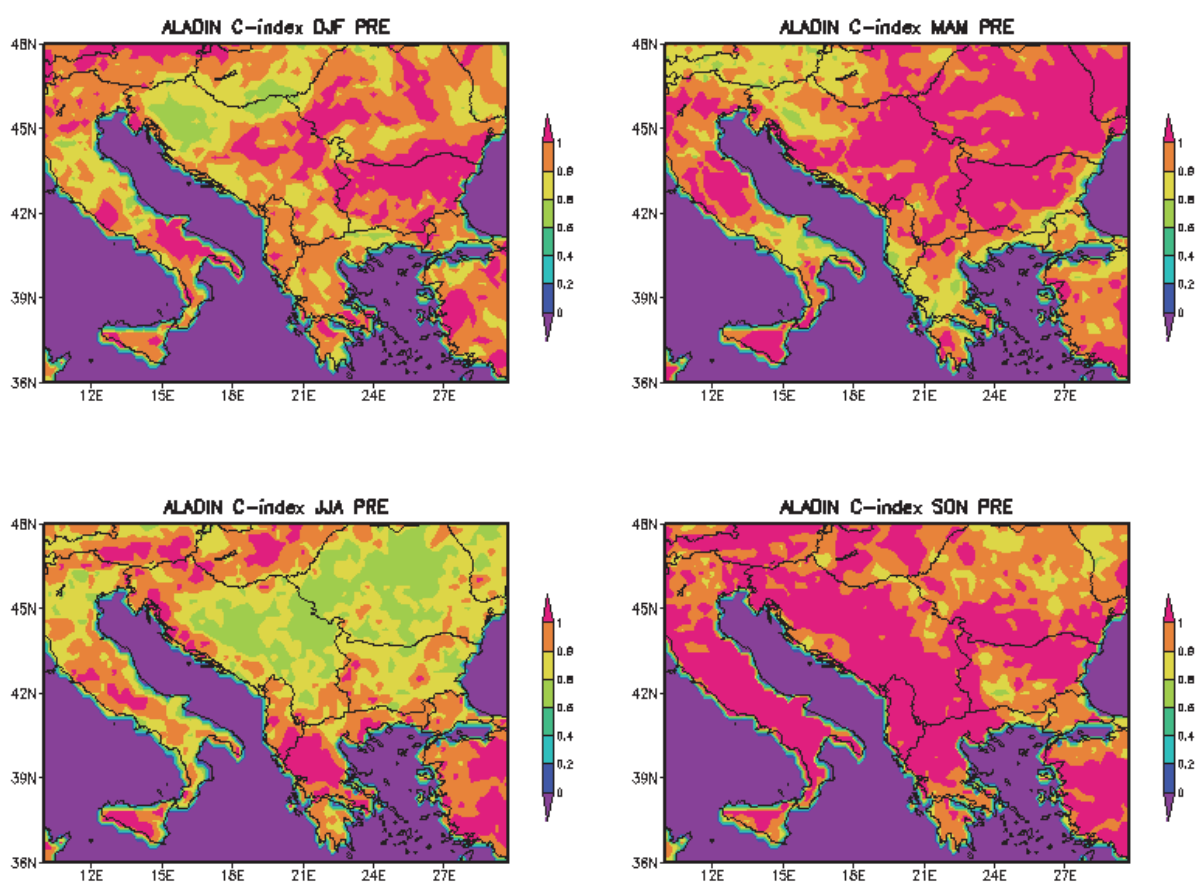

Fig. 3. Precipitation C-index distribution from ALADIN model simulation for reference (1975-2004) and future (2021-2050) periods by seasons (winter - DJF; spring - MAM; summer - JJA; autumn - SON).
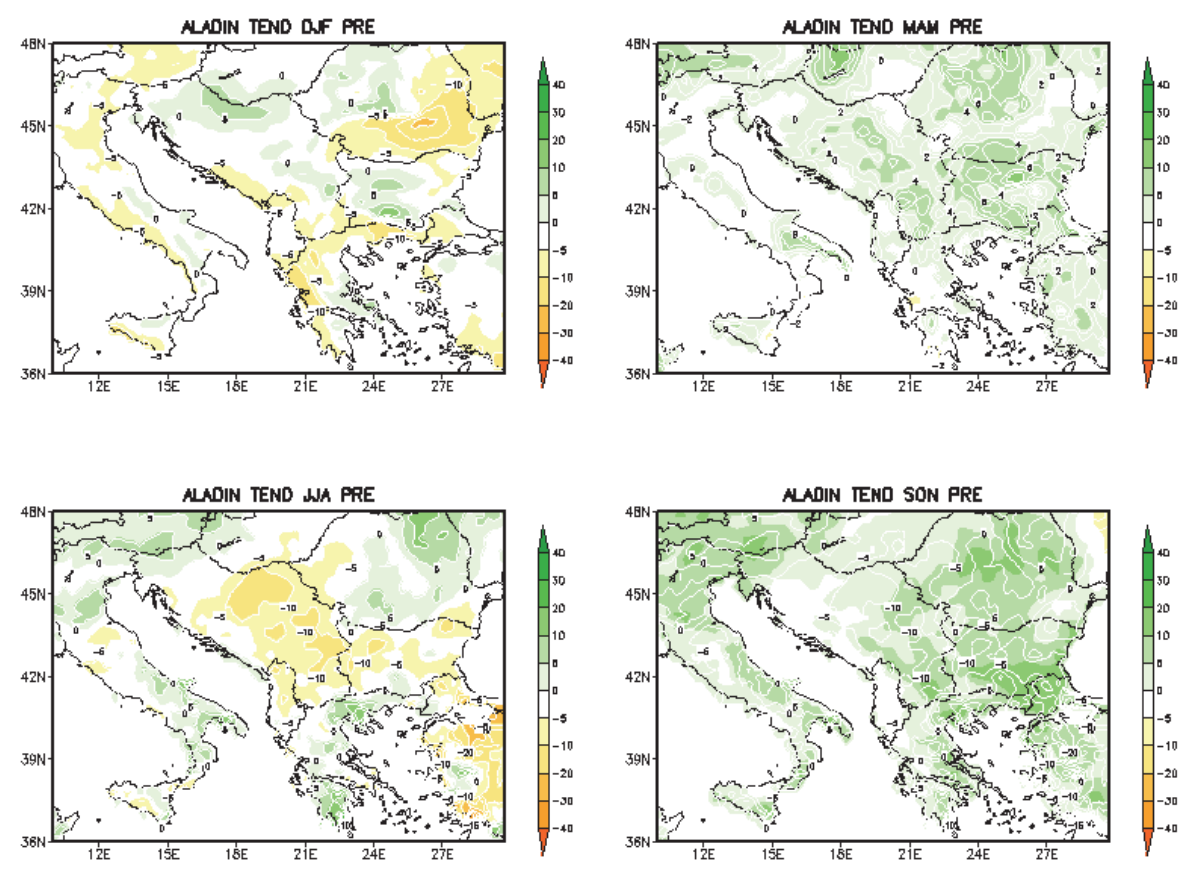

Fig. 3a. Precipitation tendencies with ALADIN model - difference between future (20212050) and reference (1975-2004) periods by seasons (winter - DJF; spring - MAM; summer - JJA; autumn - SON in \%. 

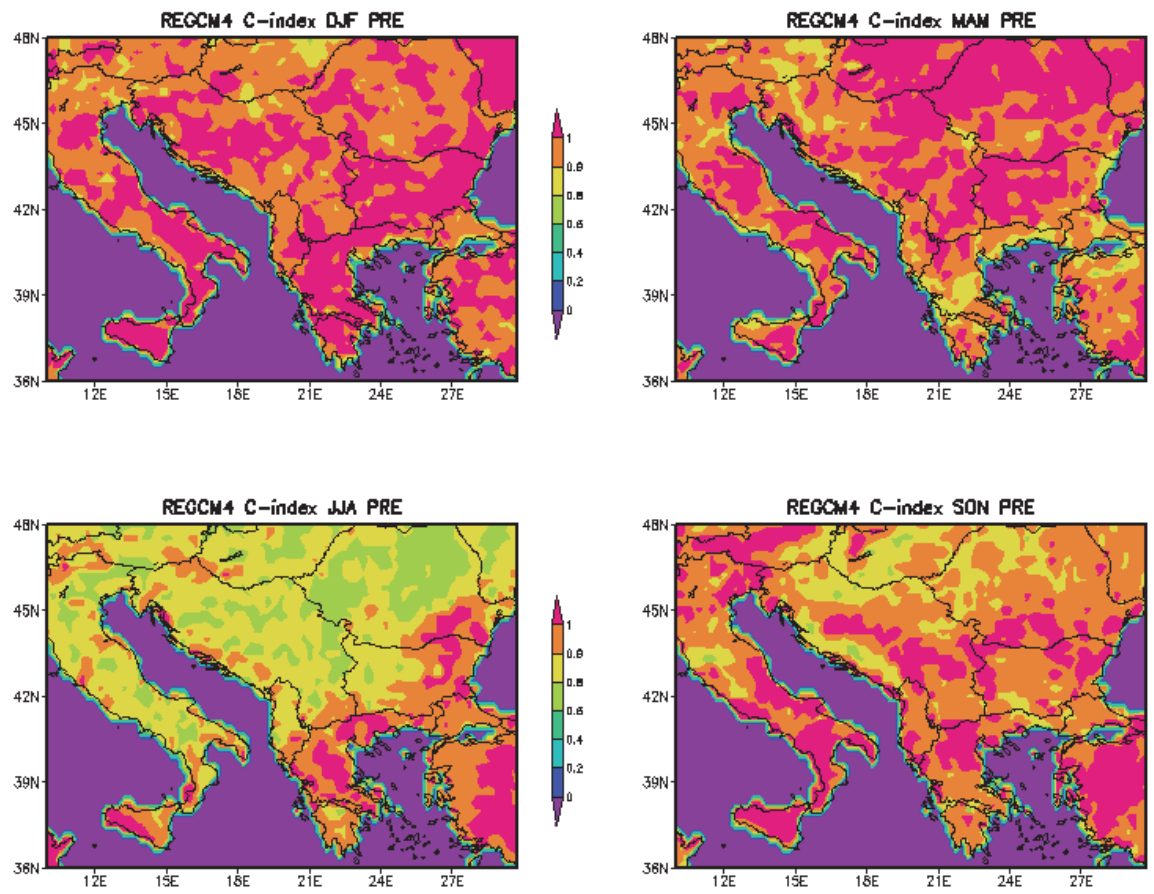

Fig. 4. Precipitation C-index distribution from RegCM4 model simulation for reference (1975-2004) and future (2021-2050) periods by seasons (winter - DJF; spring - MAM; summer - JJA; autumn - SON).
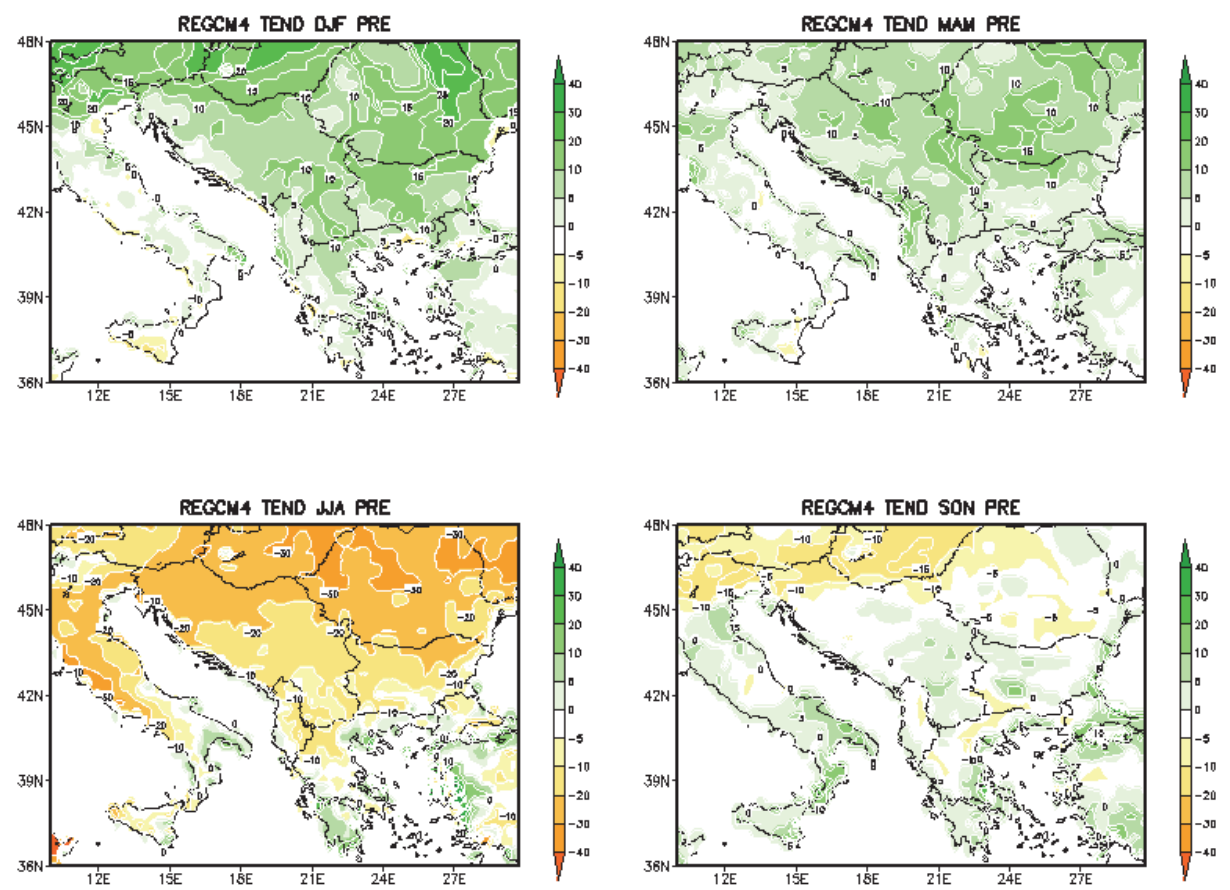

Fig. 4a. Precipitation tendencies with RegCM4 model - difference between future (20212050) and reference (1975-2004) periods by seasons (winter - DJF; spring - MAM; summer - JJA; autumn - SON) in \%. 
For both models, the biggest changes, i.e., large areas with small values of the C-index occur during the summer season. For the RegCM model,temperature $\mathrm{C}$-index maps (Fig. 2) show small values $(C<1)$ in winter and summer over the whole area and small $\mathrm{C}$-index in autumn over a significant area in the northern part of the modeled domain. In spring, $C \geq 1$ over the whole area. The RegCM precipitation C-index spatial distribution maps (Fig. 4) show small $\mathrm{C}$-index $(C<1)$ in summer (especially in the northern part of the domain). In winter and spring, the RegCM precipitation C-index (Fig. 4) is equal to or more than 1 over a significant part of domain. For the ALADIN model, precipitation C-index distribution maps (Fig. 3) show small C-index in summer over the central and north-eastern parts of the domain, where the model shows the biggest changes in precipitation. These examples illustrate the added value of applying the $\mathrm{C}$-index as a measure of climate change. If the tendencies are small (e.g., zero) and the $\sigma$ of the future climate simulation is greater than the $\sigma$ of the reference period, then the C-index may be much smaller than 1 (significant change). The opposite situation is when the value of the index is about 1 (relatively small change in climate in the sense of preserving or increasing the number of cases falling within the specified interval), and the trend is significant. In this regard, we would like to draw attention to two specific cases. The first one occurs in the spring season on the RegCM4 temperature (Fig. 2a) and C-index temperature distribution maps (Fig. 2). It is shown that in the northeastern part of the domain, where temperature warming is above $2{ }^{\circ} \mathrm{C}$, the $\mathrm{C}$-index distribution is more than 1 . The other case occurs in the autumn season on the ALADIN temperature (Fig. la) and C-index temperature distribution maps (Fig. 1), where in the northeastern parts of the domain, the temperature warming is also about $2{ }^{\circ} \mathrm{C}$, while the corresponding $\mathrm{C}$-index is greater than 1 . If the interval $(\mu-\sigma ; \mu+\sigma)$ is considered as an interval of cases with "normal" temperature or precipitation, the increasing of their number in the future is not considered as a dangerous climate change. This means, that in these cases $(C \geq 1)$ the future temperature changes will not affect the potential impact on the environment, regardless temperature warming, but it is possible to have more cases of extreme weather there. In fact, pdf deforms to higher or smaller values, remaining in the same interval. Choosing another interval can lead to other values of the C-index and even to a change in the direction of the inequality.

In some areas the differences between the tendencies of models may look more or less significant than the differences between the C-index, for example, the temperature in the models for the summer season. The reason is in the effect of combination between $\sigma$ and $\mu$. Despite of tendencies, because of redistribution, a bigger or smaller number of cases falls in the interval defined by the mean and sigma of the referent period. The differences between the $\mu$ of a future run and the $\mu$ of the control (reference) run may be compensated by a smaller $\sigma$ of the future period and vice versa. The reason for this is that the 
C-index is sensitive to changing the distribution of cases from the future period to the reference. When this change is the same for both models, then their $\mathrm{C}$-indices coincide. If the expected trends for the two models are the same, but the changes in the distributions are significant, then the C-indices differ significantly. This is the added value of this index for climate change assessment.

For better understanding of the relationship between the C-index and the tendencies, the standard deviation of the past period is shown in Figs. $5 a$ and $6 a$ for temperature and in Figs. $5 b$ and $6 b$ for precipitation for both models, which is actually in connection with the width of the selected interval. The change of standard deviation - the ratio between the future (2021-2050) and reference (1975-2004) periods is presented in Figs. $7 a$ and $8 a$ for temperature and in Figs. $7 b$ and $8 b$ for precipitation.

Figs. $5 a$ and $6 a$ show temperature standard deviation distribution $\left(\right.$ in ${ }^{\circ} \mathrm{C}$ ) from ALADIN and RegCM models, respectively, for the reference period 19752004 by seasons (winter - DJF; spring - MAM; summer - JJA; autumn - SON). Both models show the biggest temperature $\sigma$ in spring (MAM) and autumn (SON) seasons between $3.5^{\circ}$ and $5^{\circ} \mathrm{C}$. In winter (DJF), the $\sigma$ values are between $0.8^{\circ}$ and $1.6^{\circ} \mathrm{C}$ for the ALADIN model and between $1.2^{\circ}$ and $2.7^{\circ} \mathrm{C}$ for RegCM. In summer (JJA), the temperature standard deviation for ALADIN is between $1.2^{\circ}$ and $1.8^{\circ} \mathrm{C}$ and between $1.2^{\circ}$ and $2.4^{\circ} \mathrm{C}$ for RegCM, respectively.

In Figs. $5 b$ and $6 b$, precipitation standard deviation distribution (in $\mathrm{mm}$ ) from ALADIN and RegCM models, for the reference period 1975-2004 by seasons (winter - DJF; spring - MAM; summer - JJA; autumn - SON) is shown. Precipitation standard deviation distribution from the ALADIN model is between 10 and $30 \mathrm{~mm}$ in all seasons, while the RegCM standard deviation values are between 20 and $60 \mathrm{~mm}$.

The changes of values of $\sigma$ from the reference (1975-2004) to the future (2021-2050) periods are presented in Figs. 7a, 7b, 8a, and $8 b$. 

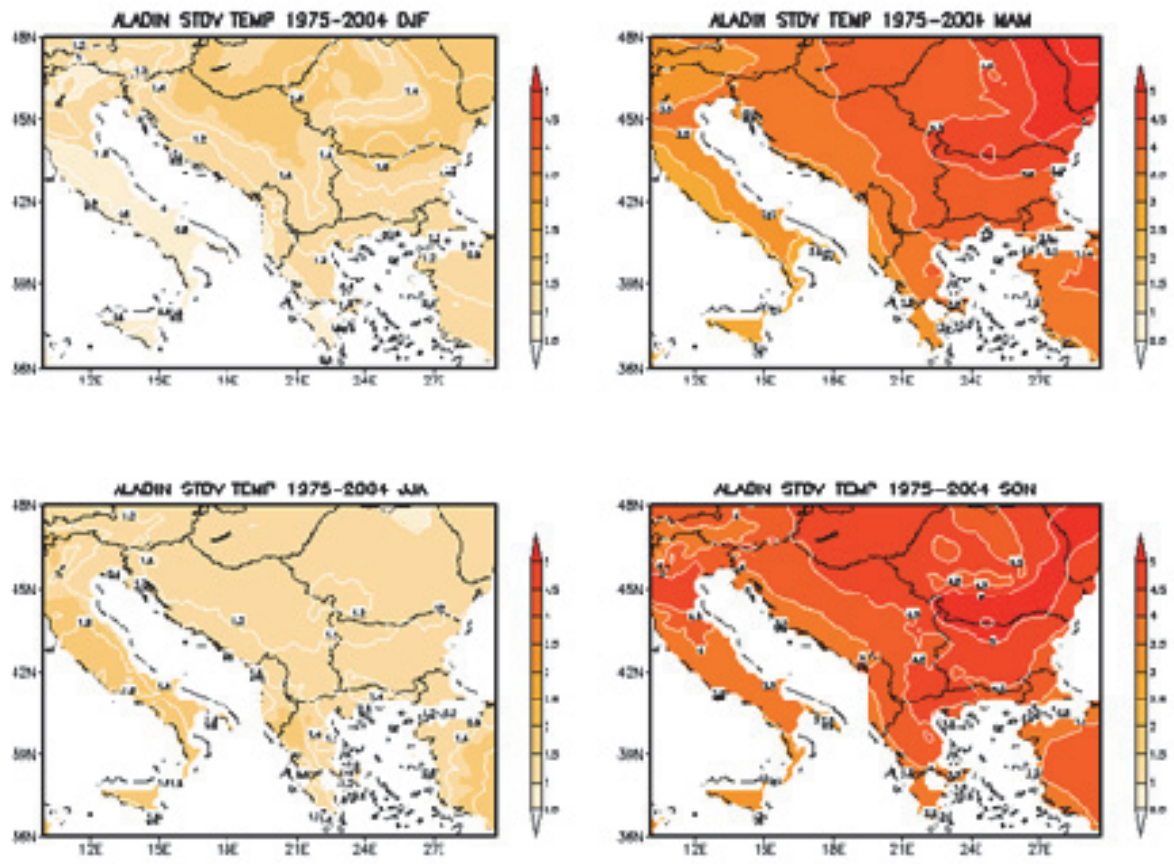

Fig. 5 a. Standard deviation of temperature (in ${ }^{\circ} \mathrm{C}$ ) from the ALADIN model for the reference period 1975-2004 by seasons (winter - DJF; spring - MAM; summer - JJA; autumn - SON)
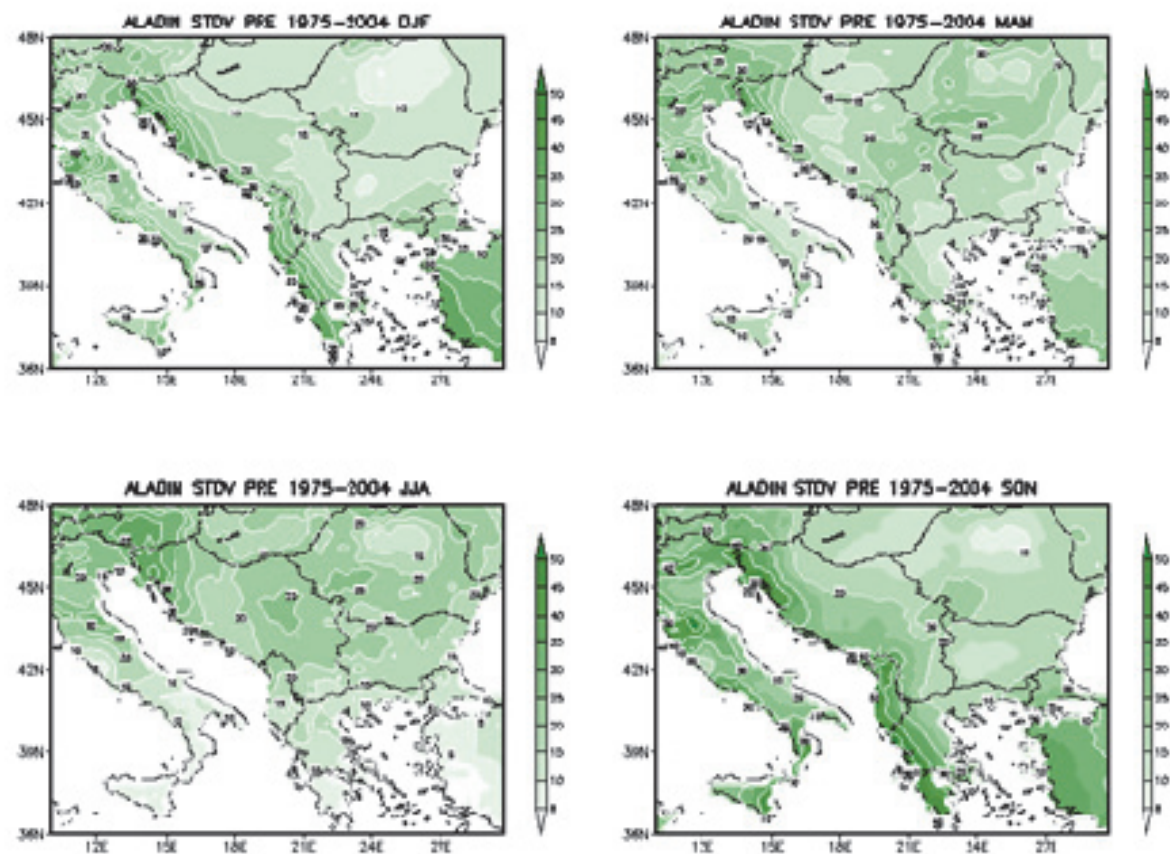

Fig. 5b. Standard deviation of precipitation (in $\mathrm{mm}$ ) from the ALADIN model for the reference period 1975-2004 by seasons (winter - DJF; spring - MAM; summer - JJA; autumn - SON). 

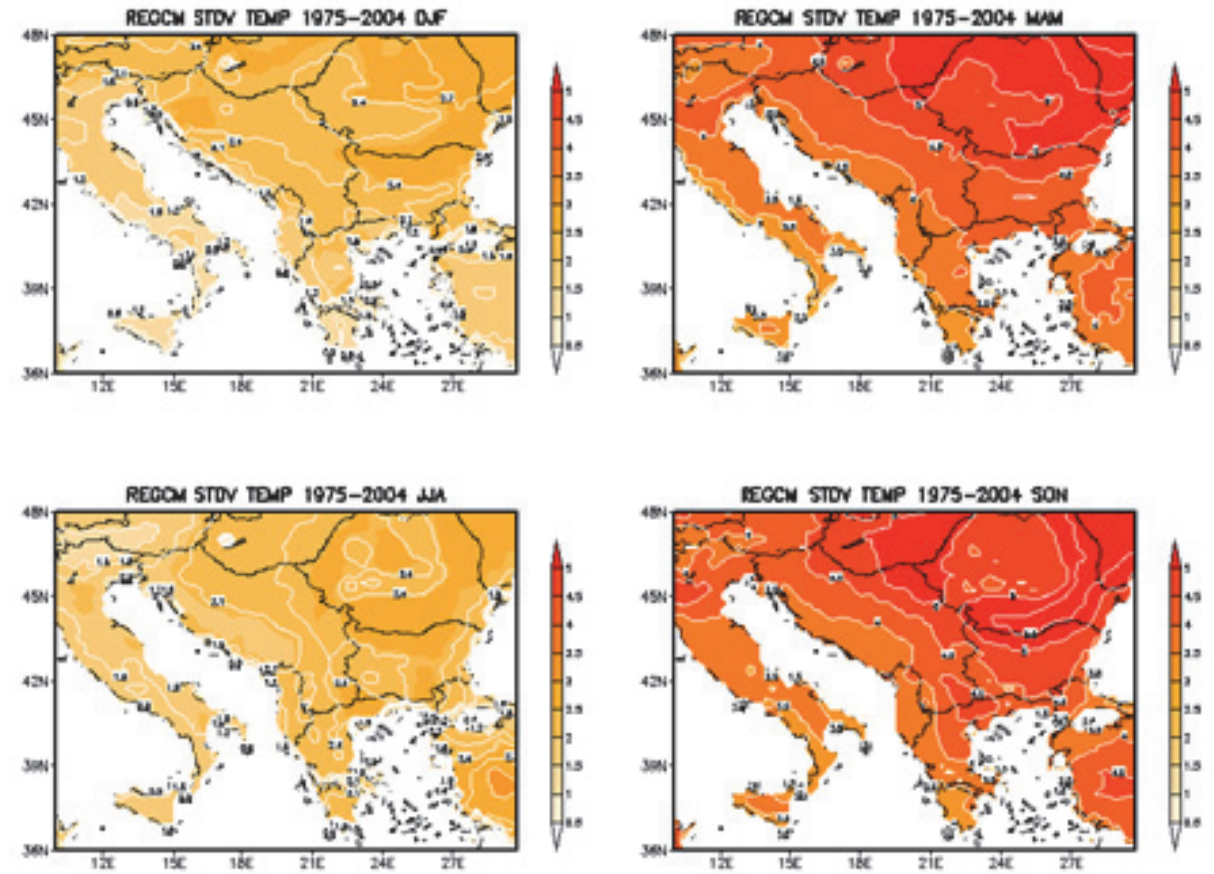

Fig. 6a. Standard deviation of temperature (in ${ }^{\circ} \mathrm{C}$ ) from the RegCM4 model for the reference period 1975-2004 by seasons (winter - DJF; spring - MAM; summer - JJA; autumn - SON).
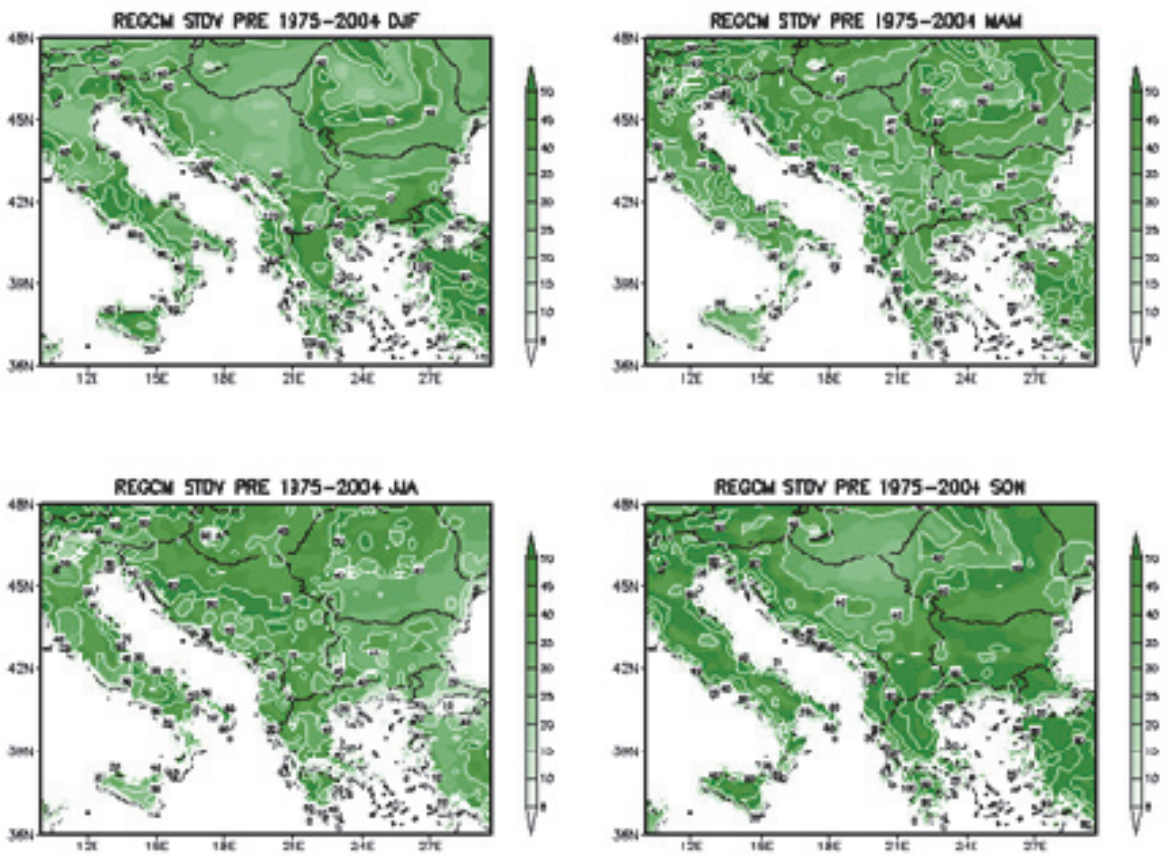

Fig. 6b. Standard deviation of precipitation (in $\mathrm{mm}$ ) from the RegCM4 model for the reference period 1975-2004 by seasons (winter - DJF; spring - MAM; summer - JJA; autumn - SON). 

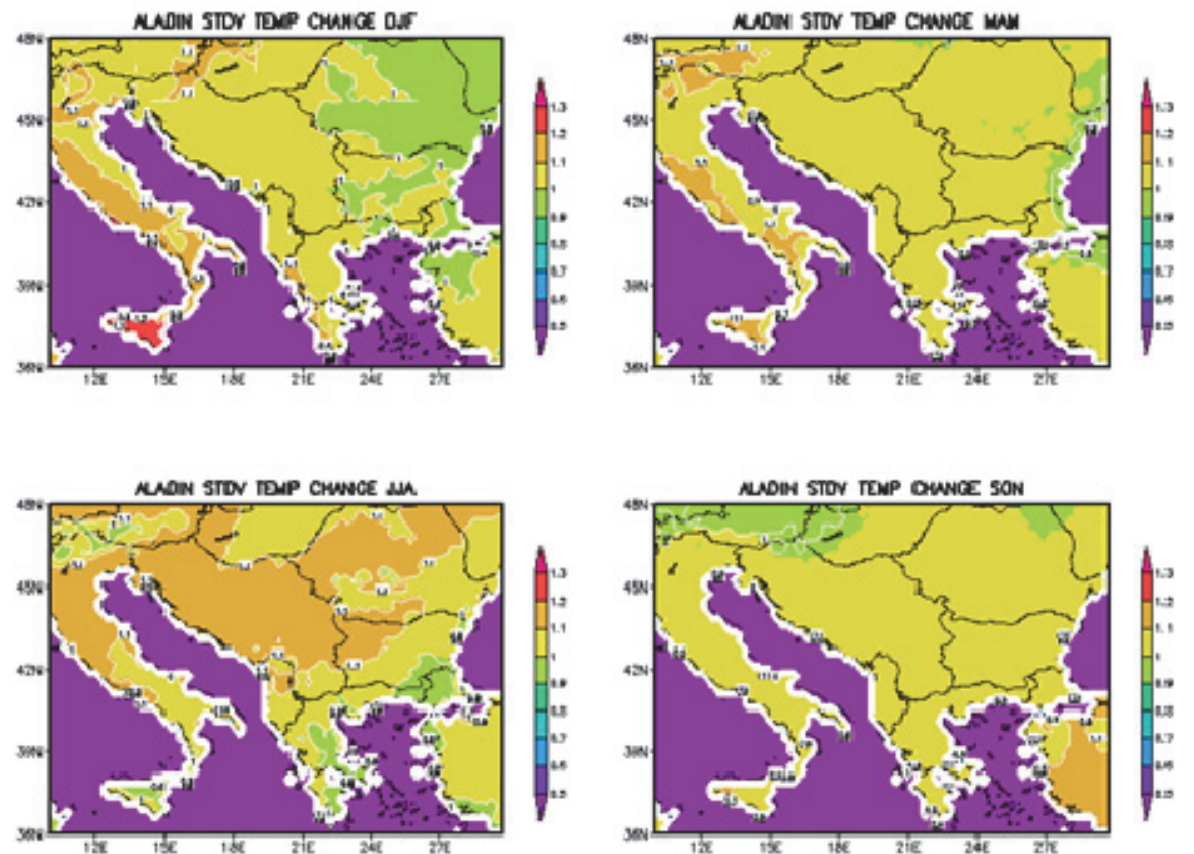

Fig. 7 a. Temperature standard deviation change (in ${ }^{\circ} \mathrm{C}$ ) from the ALADIN model - the ratio between future (2021-2050) and reference (1975-2004) periods by seasons (winter DJF; spring - MAM; summer - JJA; autumn - SON).
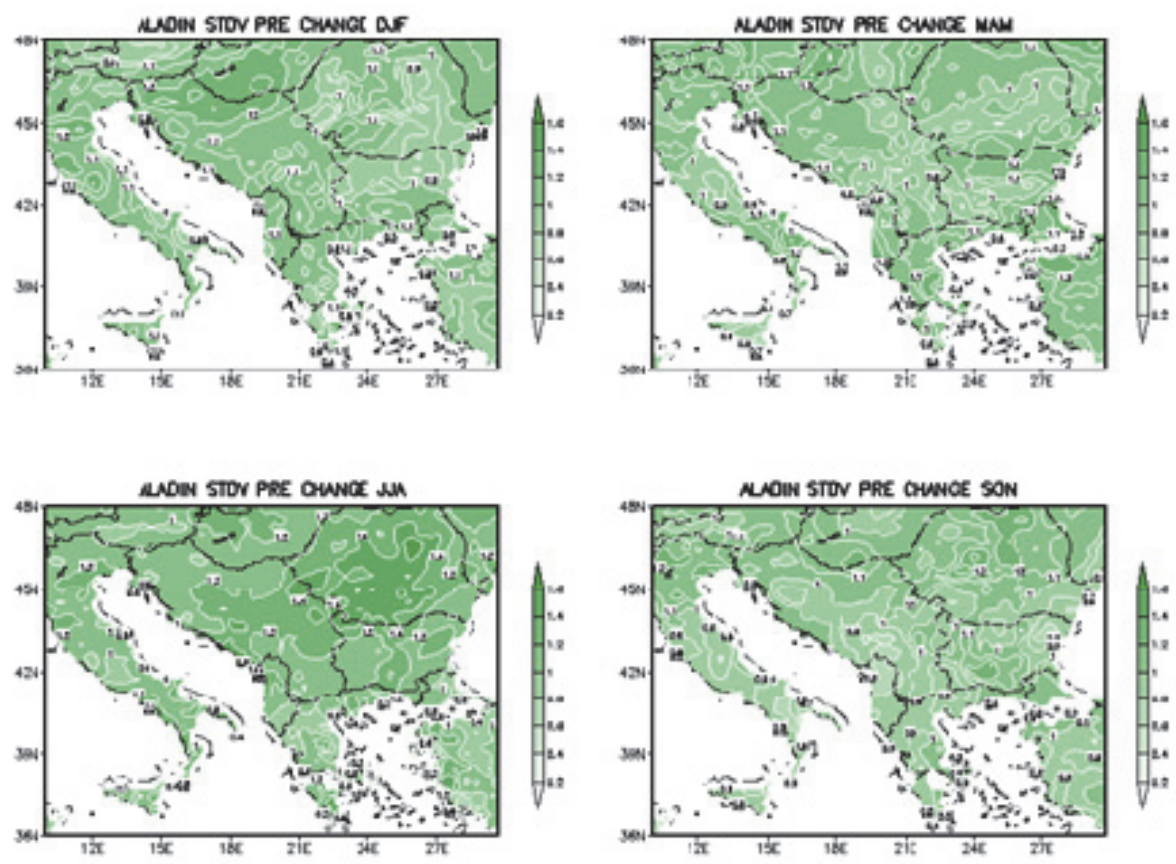

Fig. 7b. Precipitation standard deviation change (in $\mathrm{mm}$ ) from the ALADIN model - the ratio between future (2021-2050) and reference (1975-2004) periods by seasons (winter DJF; spring - MAM; summer - JJA; autumn - SON). 

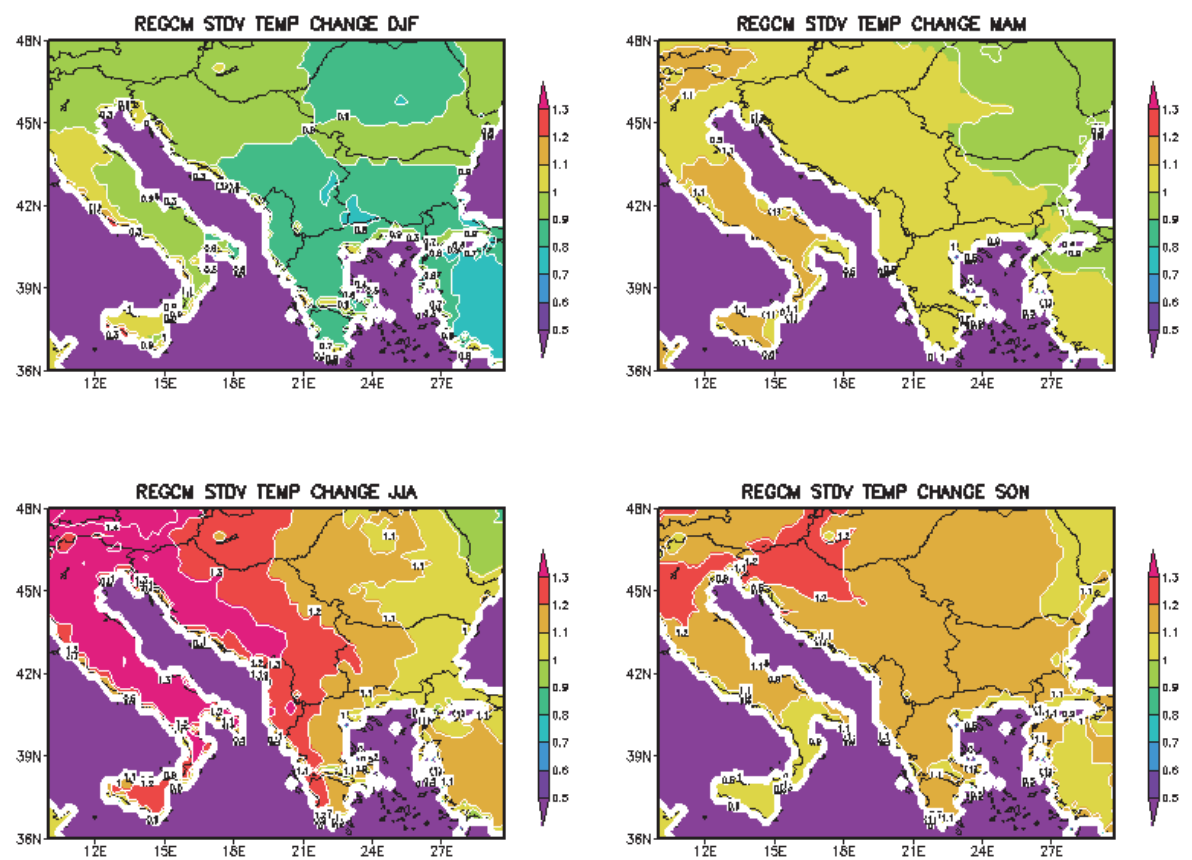

Fig. $8 a$. Temperature standard deviation change (in ${ }^{\circ} \mathrm{C}$ ) from the RegCM4 model - the ratio between future (2021-2050) and reference (1975-2004) periods by seasons (winter DJF; spring - MAM; summer - JJA; autumn - SON).
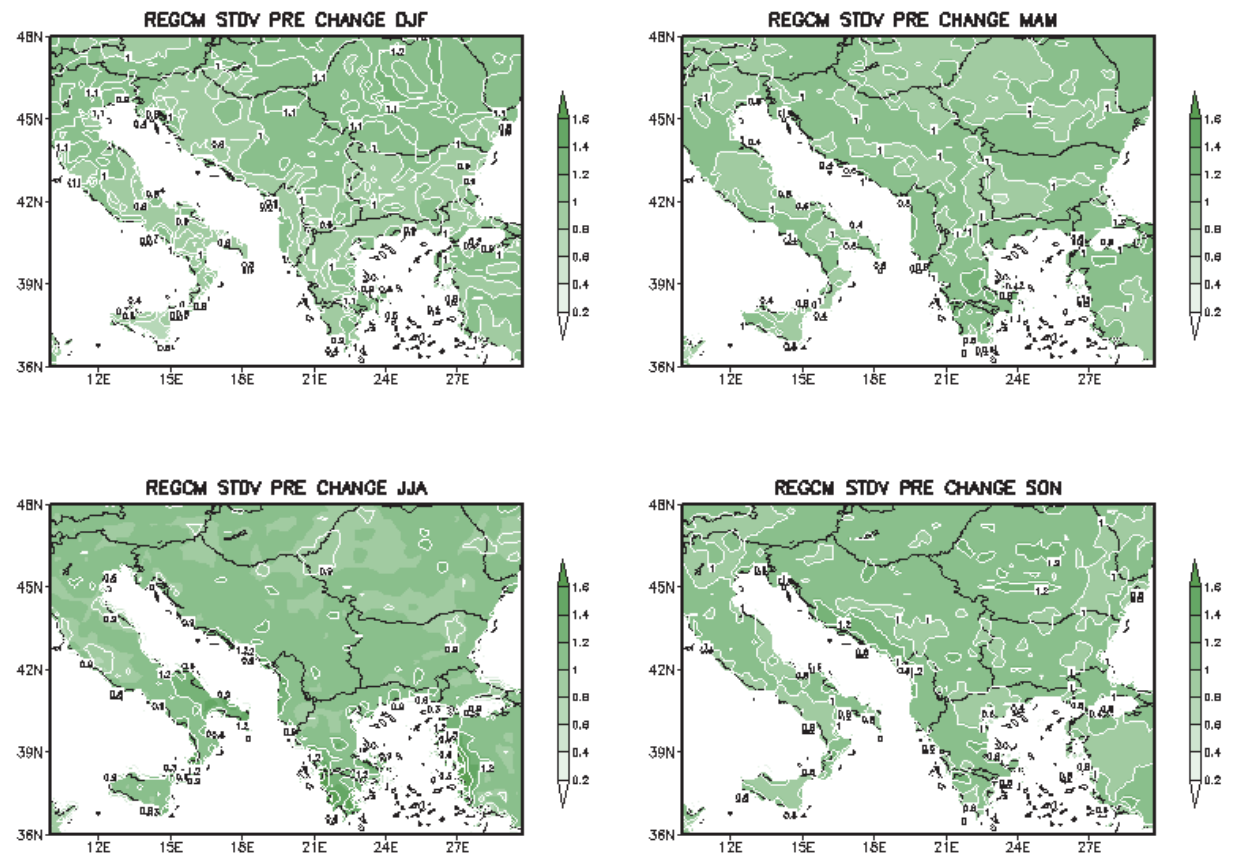

Fig. $8 b$. Precipitation standard deviation change (in $\mathrm{mm}$ ) from the ALADIN model - the ratio between future (2021-2050) and reference (1975-2004) periods by seasons (winter DJF; spring - MAM; summer - JJA; autumn - SON). 
In Figs. $7 a$ and $8 a$, the temperature standard deviation change (in ${ }^{\circ} \mathrm{C}$ ) from ALADIN and RegCM models is shown - the ratio between the $\sigma$ of future (2021-2050) and the $\sigma$ of the reference (1975-2004) periods by seasons (winter - DJF; spring - MAM; summer - JJA; autumn - SON). The biggest change in temperature standard deviation occurs in summer (JJA) between $1.0^{\circ}$ and $1.2{ }^{\circ} \mathrm{C}$ for ALADIN, where temperature changes are the biggest (Fig. 1a), $C<1$ (Fig. 1) and the temperature standard deviation is small (Fig. 5a). In JJA and SON for RegCM model the temperature standard deviation change is between $1.0^{\circ}$ and $1.3{ }^{\circ} \mathrm{C}$, and $1.1^{\circ}$ and $1.3{ }^{\circ} \mathrm{C}$, respectively, where the $\mathrm{C}$-index is small (Fig. 2) and temperature changes are the biggest (Fig. 2a).

In Figs. $7 b$ and $8 b$, precipitation standard deviation change (in $\mathrm{mm}$ ) from ALADIN and RegCM models is shown - the ratio between the $\sigma$ of future (2021-2050) and the $\sigma$ of the reference (1975-2004) periods by seasons (winter - DJF; spring - MAM; summer - JJA; autumn - SON). Both models show that the precipitation standard deviation change is between 0.4 and $1.4 \mathrm{~mm}$ in all seasons. The biggest precipitation $\sigma$ change from the $\mathrm{RegCM}$ model is in summer (JJA) and autumn (SON), where precipitation changes are the biggest (Fig. 4a) and $C<1$ (Fig. 4). The biggest precipitation $\sigma$ change from the ALADIN model is in summer (JJA) which corresponds to $C<1$ (Fig. 3) and to a decrease of the summer precipitation (Fig. 3a).

\section{Example with two BCMs}

A very simple but useful method of bias correction is the "delta change" method. Let $\mu_{r \text { ef }}$ and $\mu_{f}$ be the average of $N$ cases obtained from the reference and future periods for temperature or precipitation. Let $X_{i}(i=1, N)$ are the corresponding series of observations. The corrected range of temperature for the future is:

$$
Y_{i}^{c o r}=X_{i}+\left(\mu_{f}-\mu_{r e f}\right) .
$$

For the precipitation, relative changes are considered:

$$
Y_{i}^{c o r}=X_{i}^{*}\left(\mu_{f} / \mu_{r e f}\right) \text {. }
$$

For averages, we find:

$$
\left(\sum Y_{i}^{c o r}\right) / N=\mu_{f}^{\prime}=\left(\sum X_{i}^{c}\right) / N+\left(\mu_{f}-\mu_{r e f}\right)=\mu_{o}+\left(\mu_{f}-\mu_{r e f}\right)
$$

or

$$
\mu_{f}^{\prime}=\mu_{o}+\left(\mu_{f}-\mu_{r e f}\right) .
$$

For precipitation, respectively, we find: 


$$
\mu_{f}^{\prime}=\mu_{o}^{*}\left(\mu_{f} / \mu_{r e f}\right)
$$

Obviously, both transformations are linear and they conserve the C-index, as proved above. The trends are sufficient to assess the extent of climate change as a whole in the area of integration, and together with the $\mathrm{C}$-index they can be used as coordinates to analyze the original signal from the models. Additionally, as mentioned in Maraun (2016), the delta change method is a useful benchmark for bias correction. Indeed, this method imposes the trend towards the actually measured sequence of cases. There is no "transfer" function as in other BCMs. This is the reason to introduce a reversed analogue, using the sequence from the future period.

Let $\mu_{o}$ be the average obtained from the observation (temperature or precipitation). The corrected range of temperature for the future is:

$$
Y_{i}^{c o r}=Y_{i}+\left(\mu_{o}-\mu_{r e f}\right),
$$

and for precipitation it is:

$$
Y_{i}^{c o r}=Y_{i} *\left(\mu_{o} / \mu_{r e f}\right)
$$

For averages, we find:

$$
\left(\sum Y_{i}^{c o r}\right) / N=\mu_{f}^{\prime}=\left(\sum Y_{i}\right) / N+\left(\mu_{f}-\mu_{r e f}\right)=\mu_{f}+\left(\mu_{o}-\mu_{r e f}\right),
$$

or

$$
\mu_{f}^{\prime}=\mu_{f}+\left(\mu_{o}-\mu_{r e f}\right)=\mu_{o}+\left(\mu_{f}-\mu_{r e f}\right) .
$$

For precipitation respectively we find:

$$
\mu_{f}^{\prime}=\mu_{f}^{*}\left(\mu_{o} / \mu_{r e f}\right)=\mu_{o} *\left(\mu_{f} / \mu_{r e f}\right) .
$$

The reason for naming this method as a "reverse delta change" (RDC) is that the dependencies between the mean values for both methods have identical equations as it was proved.

Now, the transfer functions are:

$$
\left(\mu_{o}-\mu_{r e f}\right) \text { and }\left(\mu_{o} / \mu_{r e f}\right) \text {, }
$$

so the transformations are linear. As a second method we will consider the quantile mapping $(\mathrm{QM})$.

To illustrate the application of both methods and the dependence of the C-index on them, we will use observations from Cherni Vrah, the highest peak in the Vitosha Mountains. The synoptic station was established in 1935. At that time it 
was the highest mountain station. There has been no interruption of the observations, and the measurement method has been retained so far. There are no influences from industrial and urban changes or replacement, unlike at other stations.

The transfer functions defined by the Quantile-Quantile plots are shown in the next figures. To find a more general relationship between the observed and modeled data, we do not divide them into seasons. We assume that a certain observed value corresponds to a given modeled value regardless of the season. This assumption is justified by the results below. In Figs. $9 a$ and $9 b$, the transfer functions for temperature and precipitation from the ALADIN simulation are in the top right corners of the plots. The same is in Figs. 10a and 10b, but for RegCM.

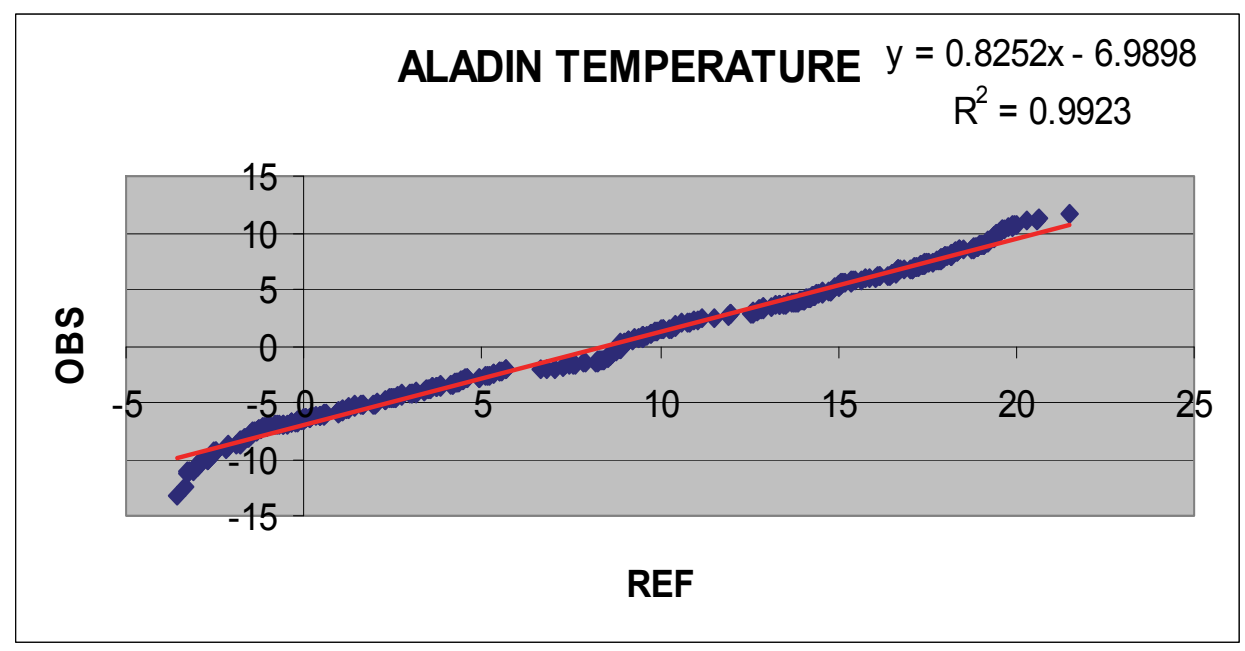

Fig. 9a. Quantile-Quantile plot comparing the distribution of observed (Cherni Vrah station) and modeled (ALADIN) temperature data for the period 1975-2004. The transfer function for temperature from the ALADIN simulation is in the top right corner of the plot.

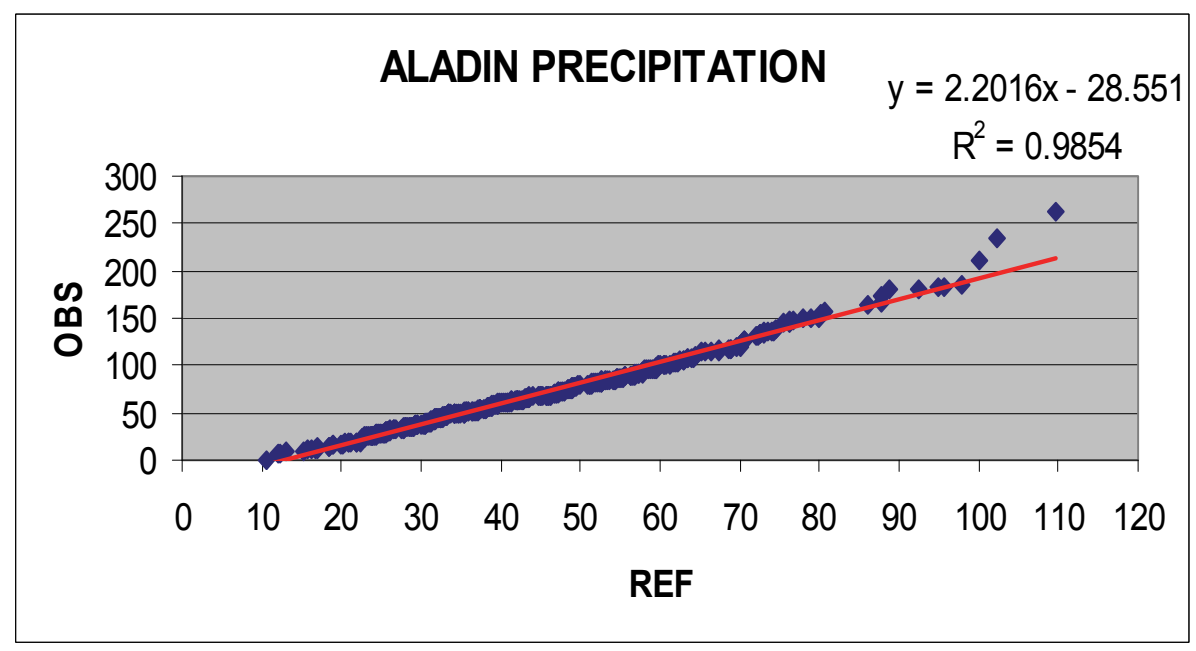

Fig. 9b. Quantile-Quantile plot comparing the distribution of observed (Cherni Vrah station) and modeled (ALADIN) precipitation data for the period 1975-2004. The transfer function for precipitation from the ALADIN simulation is in the top right corner of the plot. 


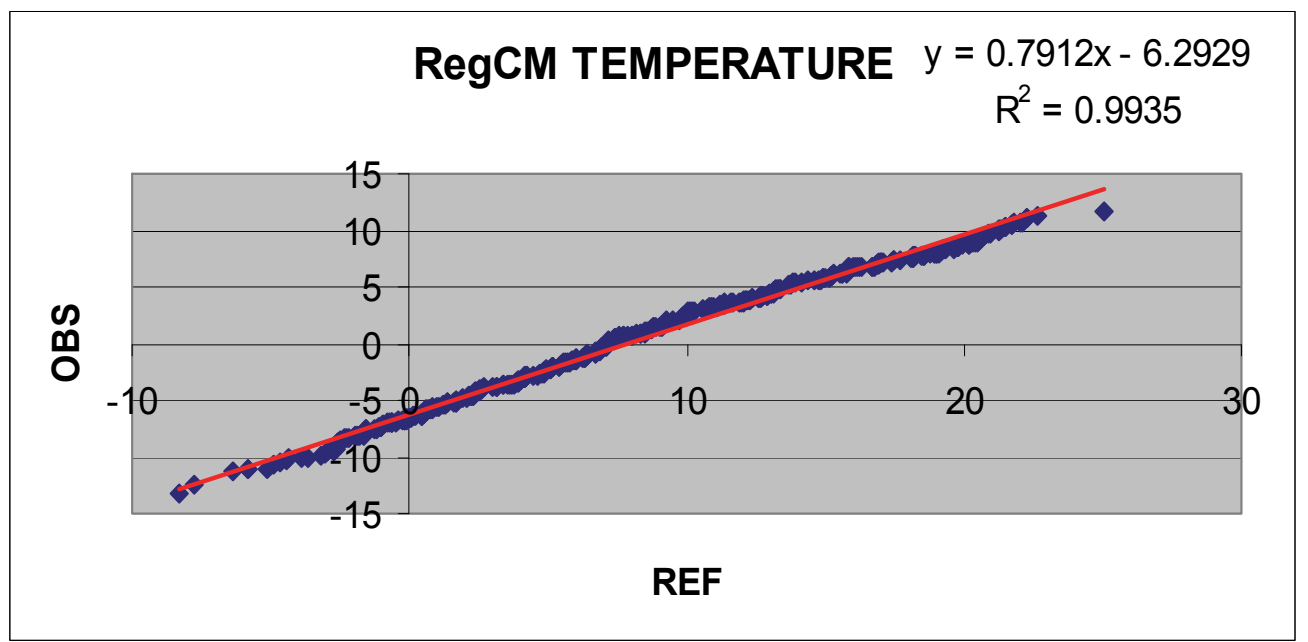

Fig. 10a. Quantile-Quantile plot comparing the distribution of observed (Cherni Vrah station) and modelled (RegCM4) temperature data for the period 1975-2004. The transfer function for temperature from the RegCM4 simulation is in the top right corner of the plot.

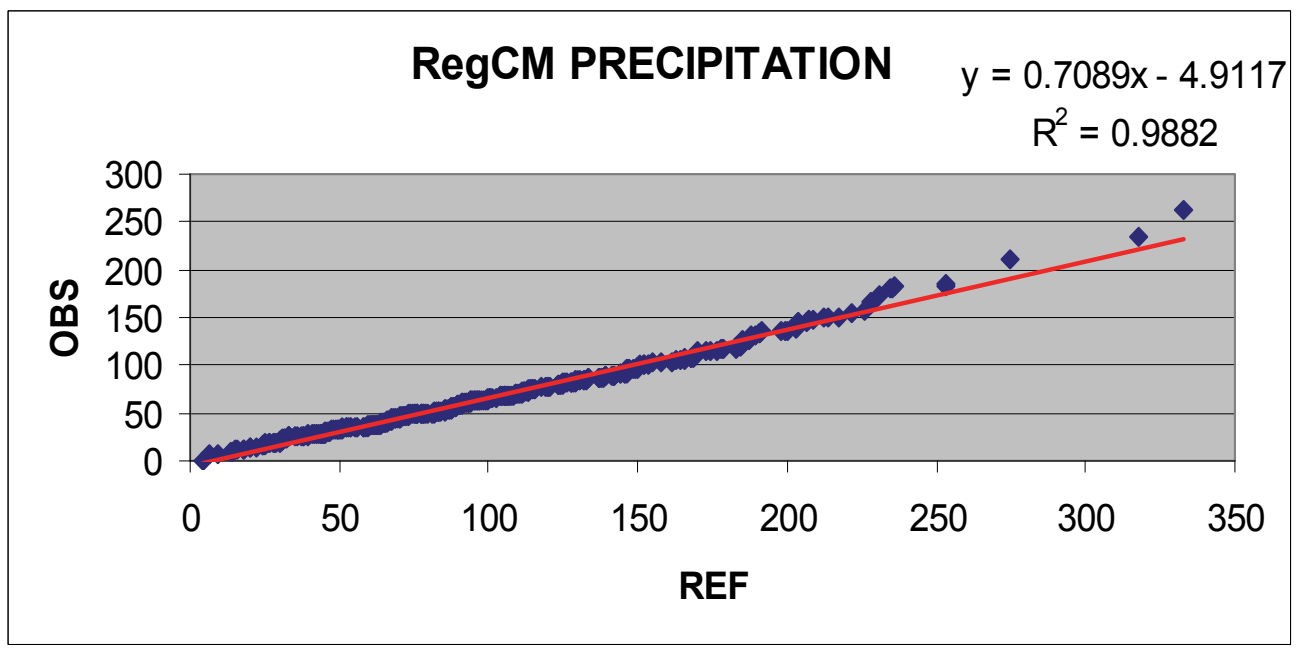

Fig. 10b. Quantile-Quantile plot comparing the distribution of observed (Cherni Vrah station) and modelled (RegCM4) precipitation data for the period 1975-2004. The transfer function for precipitation from the RegCM4 simulation is in the top right corner of the plot.

As it can be seen, linear functions approximate very well the main part of the quantiles. The $\mathrm{C}$-index should be determined before and after applying the $\mathrm{BCM}$, i.e., the transfer functions should be applied to the original data from the reference 
run according to Eq. (2). Then it happens, that all cases are in this linear part at certain intervals (mean \pm standard deviation). The results of these methods are presented in Table 1 for temperature and in Table 2 for precipitation.

Table 1. Mean, standard deviation, and C-index before ( $\mu, \sigma$, and C-index) and after $(\mu$, $\sigma$ ' and C-index') applying BCMs (RDC - reverse delta change; QM - quantile mapping) for temperature by using ALADIN and RegCM4 models.

\begin{tabular}{ccccccc}
\hline \hline & $\boldsymbol{\mu}$ & $\boldsymbol{\sigma}$ & $\boldsymbol{C}$-index & $\boldsymbol{\mu}^{\prime}$ & $\boldsymbol{\sigma}^{\prime}$ & C-index' $^{\prime}$ \\
\hline \hline $\begin{array}{c}\text { ALADIN } \\
\text { RDC }\end{array}$ & 8.741668 & 7.500746 & 0.9839572 & 0.2236101 & 7.500748 & 0.9839572 \\
$\begin{array}{c}\text { ALADIN } \\
\text { QM }\end{array}$ & 8.741668 & 7.500746 & 0.9839572 & 0.2238232 & 6.189616 & 0.9839572 \\
$\begin{array}{c}\text { RegCM } \\
\text { RDC }\end{array}$ & 8.236060 & 7.827411 & 0.9627907 & 0.2236048 & 7.827417 & 0.9627907 \\
$\begin{array}{c}\text { RegCM } \\
\text { QM }\end{array}$ & 8.236060 & 7.827411 & 0.9627907 & 0.2234672 & 6.193053 & 0.9627907 \\
\hline
\end{tabular}

Table 2. Mean, standard deviation, and C-index before ( $\mu, \sigma$, and $\mathrm{C}$-index) and after $(\mu$, $\sigma$ ', and C-index') applying BCMs (RDC - reverse delta change; QM - quantile mapping) for precipitation by using ALADIN and RegCM4 models.

\begin{tabular}{ccccccc}
\hline \hline & $\boldsymbol{\mu}$ & $\boldsymbol{\sigma}$ & C-index & $\boldsymbol{\mu}^{\prime}$ & $\boldsymbol{\sigma}^{\prime}$ & C-index' $^{\prime}$ \\
\hline \hline ALADIN & 43.83639 & 17.93699 & 1.024096 & 67.95747 & 27.80694 & 1.024096 \\
$\quad$ RDC & & & & & & \\
ALADIN & 43.83639 & 17.93699 & 1.024096 & 67.95921 & 39.49014 & 1.024096 \\
$\quad$ QM & & & & & & \\
$\begin{array}{c}\text { RegCM } \\
\text { RDC }\end{array}$ & 102.7887 & 55.78205 & 0.9433199 & 67.95747 & 36.87967 & 0.9433199 \\
$\begin{array}{c}\text { RegCM } \\
\text { QM }\end{array}$ & 102.7887 & 55.78205 & 0.9433199 & 67.95520 & 39.54397 & 0.9433199 \\
\hline
\end{tabular}

In the tables $\mu, \sigma, \mathrm{C}$-index, $\mu^{\prime}, \sigma^{\prime}$, and $\mathrm{C}$-index' are the mean, the standard deviation, and the $\mathrm{C}$-index before and after applying the $\mathrm{BCM}$. The significant changes in the mean values are mainly due to the distance between the grid points of the models and the station location as well as the topography in model points. We used the closest point (the models have different grids) without any interpolations. The BCM should overcome these discrepancies. Any method for localization will add its own error. We can see that in the results, after these different corrections, the mean values are almost identical. For the temperature, the differences between $\sigma$ and $\sigma^{\prime}$ after using the RDC for any of the models are 
insignificant. The standard deviations of temperature and precipitation have similar values after applying both methods for both models. Indices $\mathrm{C}$ do not change as expected. Their values for temperature are practically identical for both models. For the precipitation they are on both sides of the benchmark " 1 ".

Another example of using the proposed index is the overall assessment of climate change in the integration domain by means of graphs in the coordinate system of the trend and the C-index. In Figs. 11a, 11b, 12a, and $12 b$ examples are given for temperature and precipitation from ALADIN and RegCM, respectively. The values in the grid points are placed in tendencies-C-index coordinate system.

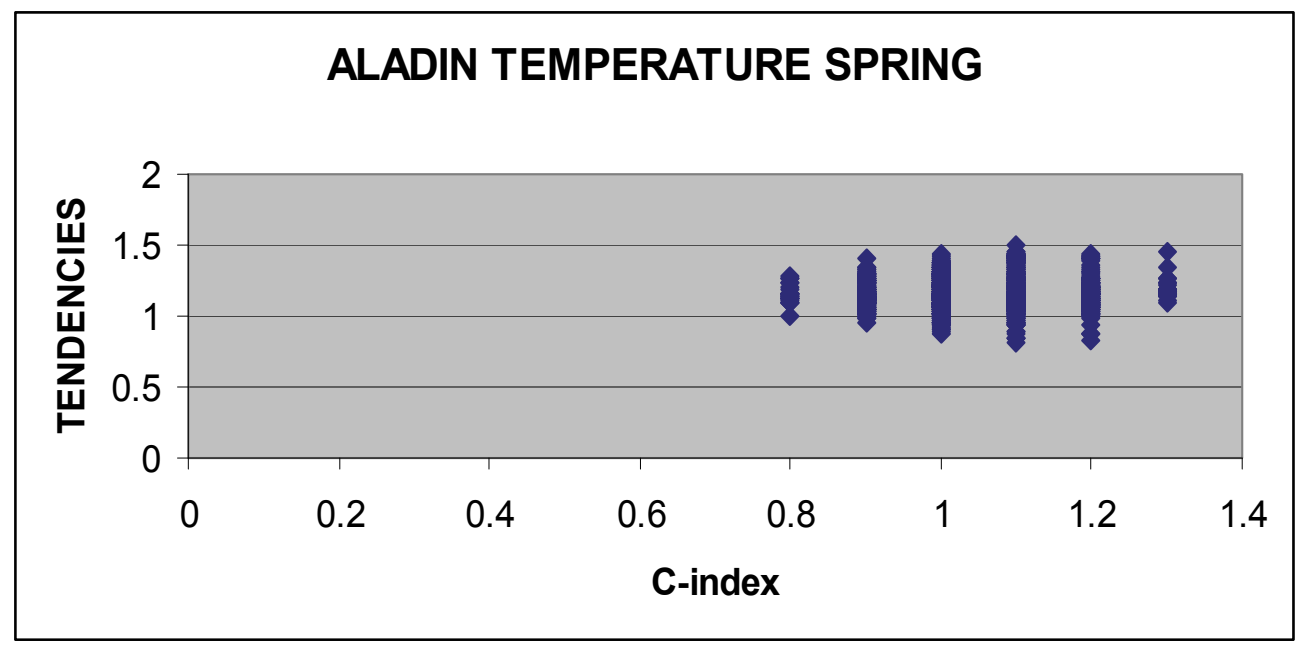

Fig. 11a. Tendencies-C-index chart of temperature during the spring season for the ALADIN model.

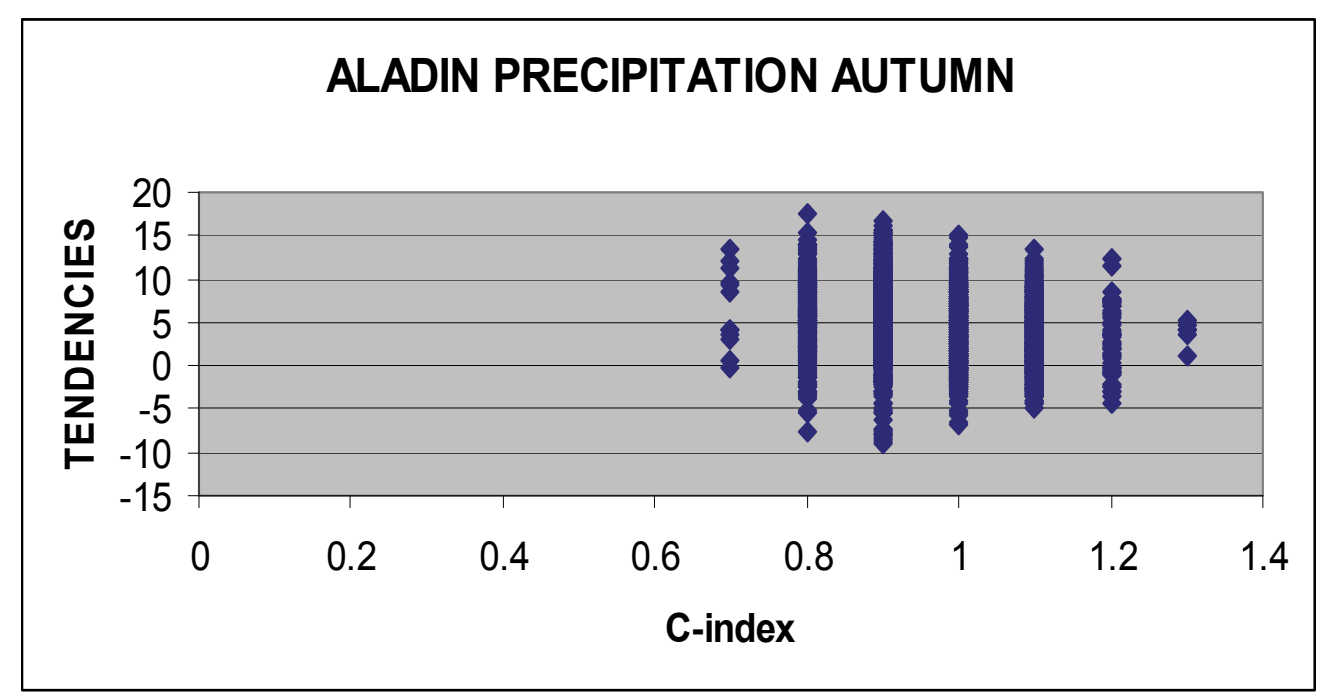

Fig. 11b. Tendencies-C-index chart of precipitation during the autumn season for the ALADIN model. 


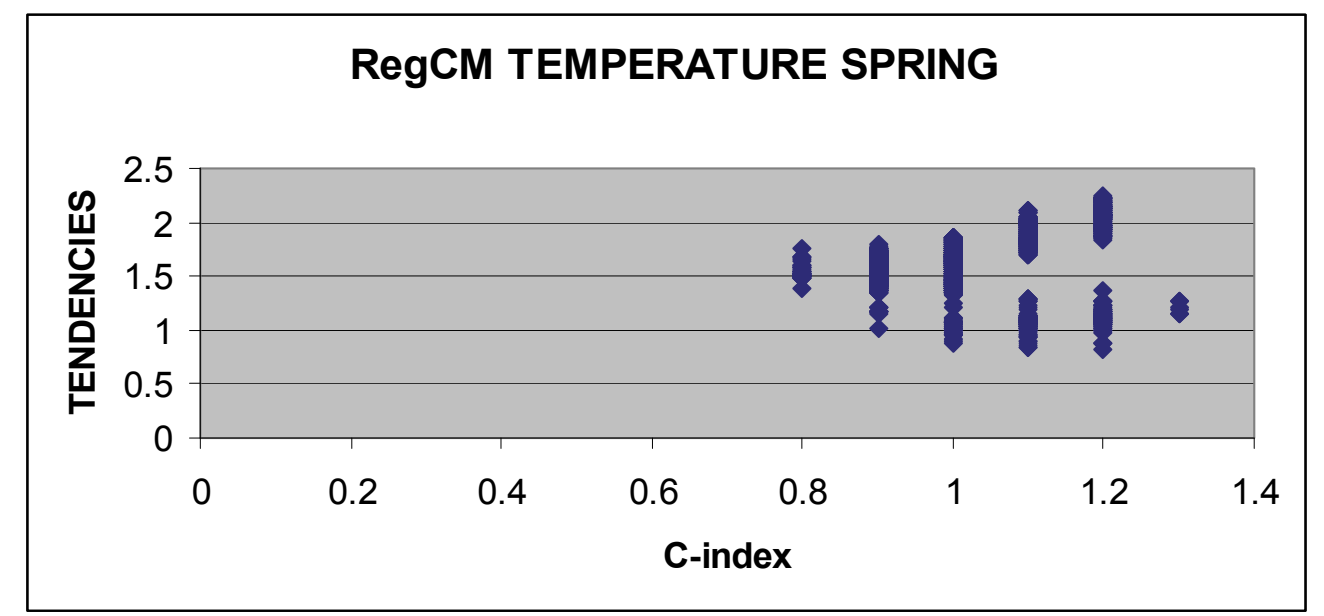

Fig. 12a. Tendencies-C-index chart of temperature during the spring season for the RegCM4 model.

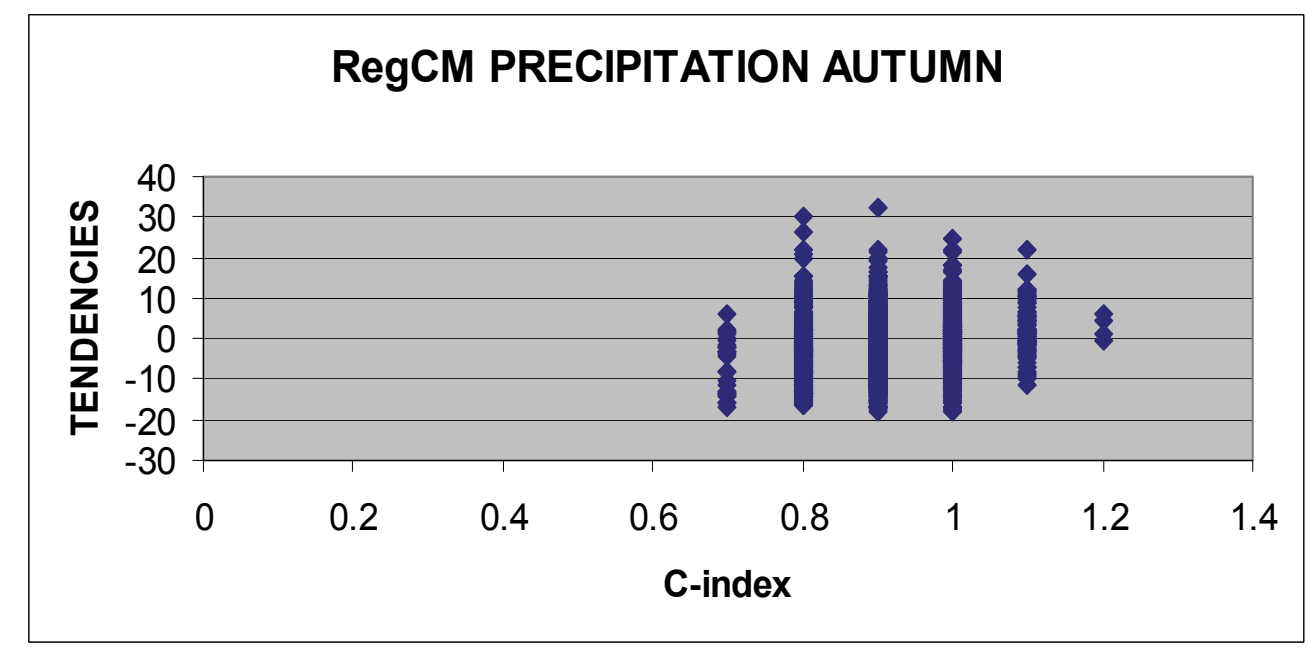

Fig. 12b. Tendencies-C-index chart of precipitation during the autumn season for the RegCM4 model.

Both models have significant munber of cases with $C \geq 1$, i.e., these cases remain or are moved within the interval determined by the reference simulations. In spring, ALADIN shows tendencies mainly in the interval $1-1.5^{\circ} \mathrm{C}$. RegCM predicts two areas with different temperature tendencies. The first one have tendencies in the interval $1.5-2.3{ }^{\circ} \mathrm{C}$ and the second one in interval $0.3-1.5{ }^{\circ} \mathrm{C}$. Positive rainfall trends in autumn are up to $20 \%$ for ALADIN and RegCM. Negative rainfall trends are $10 \%$ for ALADIN and up to $20 \%$ for RegCM. Generally speaking, RegCM is warmer and drier than ALADIN during these seasons, but both models have a significant number of cases with $\mathrm{C} \geq 1$, especially for the temperature. Similar diagrams make analyses easier than using maps. 


\section{Conclusion}

All ETCCDI indices analyzed in Dosio (2016) are various measures for assessing climate change. The proposed $\mathrm{C}$-index provides two options. The first is to assess the structure of climate change in the future period from the point of view of an "observer" of the climate in the control (reference) period. The other option is to keep the index when applying the "transfer function" as a requirement not to lose the original climate change signal.

From the examples above, it can be seen that in both models there are large areas with the same $C$-index, determined by the interval $(\mu-\sigma ; \mu+\sigma)$. If a bias correction method is applied, the distribution of $\mathrm{C}$-index should be the same, i.e., the figures shown above should remain the same.

The C-index can be defined for each interval $(\delta 1, \delta 2)$ of different meteorological elements or indices. Within this range, the properties mentioned above will be retained. This index can be considered as a measure of "climate change" at this interval. The smaller the index, the bigger the change in the climate. Another possibility is to use it as an indicator for changing the signal of the model. If the index changes, the logic of the model simulations will be lost. Then the future climate after bias correction will look differently for the "observer" from the reference period.

The determination of the interval depends on the analysis to be made. In the examples presented here, we followed the assumption that the extreme weather is outside the range defined by the mean and standard deviation. If the goal is to assess the change above or below some threshold, then we must take into account the distribution error in the reference period. For example, many models are colder during the reference period and a priori defined threshold may not exist. This indicates an other fact, that should be taken into account. As mentioned in Dosio (2016): "Results show that absolute-threshold indices are largely affected by bias adjustment, as they depend strongly on both the present mean climate value (usually largely biased in the original RCMs) and its shift under climate change". The stability of the proposed index depends not only on the error of the model (the linear component has no impact on the index as shown above) but also on the number of cases falling in the chosen interval. A small number will lead to its instability. Methods providing the automatic presence of a significant number of cases, such as using standard deviation, are suitable for determining a stable index.

Acknowledgments: The authors wish to thank the Earth System Physics group at the Abdus Salam International Centre of Theoretical Physics (ICTP) for providing free data and software, and the Program for career development of young scientists at the Bulgarian Academy of Sciences. 


\section{References}

Cattaneo, L., Rillo, V., Manzi, M.P., Villani, V., and Mercogliano, P., 2015: Clime: climate data processing in GIS environment. CMCC Research Papers RP0257.

Collins, W.J., Bellouin, N., Doutriaux-Boucher, M., Gedney, N., Halloran, P., Hinton, T., Hughes, J., Jones, C.D., Joshi, M., Liddicoat, S., Martin, G., O'Connor, F., Rae, J., Senior, C., Sitch, S., Totterdell, I., Wiltshire, A., and Woodward, S., 2011: Development and evaluation of an Earthsystem model - HadGEM2. Geosci. Model Dev. Discuss. 4, 997-1062. https://doi.org/10.5194/gmdd-4-997-2011

Dai, A., 2006: Precipitation Characteristics in Eighteen Coupled Climate Models. J. Climate 19, 4605 4630. https://doi.org/10.1175/JCLI3884.1

Deque, M., 2007: Frequency of precipitation and temperature extremes over France in an anthropogenic scenario: Model results and statistical correction according to observed values. Glob. Planet. Change 57, 16-26. https://doi.org/10.1016/j.gloplacha.2006.11.030

Dosio, A., 2016: Projections of climate change indices of temperature and precipitation from an ensemble of bias-adjusted high-resolution EURO-CORDEX regional climate models. $J$. Geophys. Res. Atmos. 121, 5488-5511. https://doi.org/10.1002/2015JD024411

Ehret, U., Zehe, E., Wulfmeyer, V., Warrach-Sagi, K., Liebert, J., 2012: Should we apply bias correction to global and regional climate model data? Hydrol. Earth Syst. Sci. Discuss 9, 53555387. https://doi.org/10.5194/hessd-9-5355-2012

Giorgi, F, Coppola, E, Solmon, F, Mariotti, L, Sylla, MB, Bi, X, Elguindi, N, Diro, GT, Nair, V, Giuliani, G, Turuncoglu, UU, Cozzini, S, Güttler, I, O'Brien, TA, Tawfik, AB, Shalaby, A, Zakey, AS, Steiner, AL, Stordal, F, Sloan, LC and Brankovic, C, 2012: RegCM4: Model description and preliminary tests over multiple CORDEX domains. Climate Res. 52, 7-29. https://doi.org/10.3354/cr01018

Grillakis, M.G., Aristeidis G. Koutroulis, Ioannis N. Daliakopoulos, and Ioannis K. Tsanis, 2017: A method to preserve trends in quantile mapping bias correction of climate modeled temperature. Earth Syst. Dynam. 8, 889-900. https://doi.org/10.5194/esd-8-889-2017

Haerter, J.O., B. Eggert, C. Moseley, C. Piani and P. Berg, 2015: Statistical precipitation bias correction of gridded model data using point measurements. Geophys. Res. Lett. 42, 1919-1929. https://doi.org/10.1002/2015GL063188

Hagemann, S., Chen, J.O. Harter, J. Heinke, D. Gerten, and C. Piani, 2011: Impact of a statistical bias correction on the projected hydrological changes obtained from three GCMs and two hydrology models. Journal of Hydrometeorology. https://doi.org/10.1175/2011 JHM1336.1

Huth, R., 1999: Statistical downscaling in central Europe: evaluation of methods and potential predictors. Clim. Res. 13, 91-101. https://doi.org/10.3354/cr013091

Maraun, D., 2016: Bias Correcting Climate Change Simulations - a Critical Review. Curr. Clim. Change Rep. https://doi.org/10.1007/s40641-016-0050-x

Mearns, L.O., Bogardi, I., Giorgi, F., Matyasovszky, I., and M. Palecki, 1999: Comparison of Climate Changes Scenarios Generated from Regional Climate Model Experiments and Statistical Downscaling. J. Geophys. Res. 104, 6603-6621. https://doi.org/10.1029/1998JD200042

Navarro-Racines, C.E., Tarapues-Montenegro, J.E., and Ramírez-Villegas, J.A., 2015: Bias-correction in the CCAFS-Climate Portal: A description of methodologies. Decision and Policy Analysis (DAPA) Research Area. International Center for Tropical Agriculture (CIAT). Cali, Colombia.

Piani, C., Haerter, J.O., and Coppola, E., 2010: Statistical bias correction for daily precipitation in regional climate models over Europe. Theor. Appl. Climatol. 99, 187-192. https://doi.org/10.1007/s00704-009-0134-9

Pierce, D.W., Cayan, D.R., Maurer, E.P., Abatzoglou, J.T., and Hegewisch K.C., 2015: Improved bias correction techniques for hydrological simulations of climate change. J. Hydrometeorol. 16, https://doi.org/10.1175/JHM-D-14-0236.1

Sippel, S., F.E.L. Otto, M. Forkel, M. R. Allen, B.P. Guillod, M. Heimann, M. Reichstein, S. I. Seneviratne, K. Thonicke, and M.D. Mahecha, 2016: A novel bias correction methodology for climate impact simulations. Earth Syst. Dynam. 7, 71-88. https://doi.org/10.5194/esd-7-71-2016 
Sun, Y., S. Solomon, A. Dai, and R.W. Portmann, 2006: How often does it rain? J. Climate 19, 916934. https://doi.org/10.1175/JCLI3672.1

Switanek, M.B., Peter A. Troch, C.L. Castro, A. Leuprecht, H.-I Chang, R. Mukherjee, and E.M.C. Demaria, 2017: Scaled distribution mapping: a bias correction method that preserves raw climate model projected changes. Hydrol. Earth Syst. Sci. 21, 2649-2666. https://doi.org/10.5194/hess-21-2649-2017

Teutschbein, C., Wetterhall, F., and Seibert, J., 2011: Evaluation of different downscaling techniques. Clim Dynam.37, 2087-2105. https://doi.org/10.1007/s00382-010-0979-8

Thomson, A.M., Calvin, K.V., Smith, S.J., Kyle, G.P., Volke, A., Patel, P., Delgado-Arias, S., BondLamberty, B., Wise, M.A., Clarke, L.E., and Edmonds, J.A., 2011: RCP4.5: a pathway for stabilization of radiative forcing by 2100 . Climatic Change 109, 77-94.

https://doi.org/10.1007/s10584-011-0151-4 